\title{
LA GESTIÓN DE RIESGOS EN LOS DESTINOS TURÍSTICOS DE MONTAÑA EN CHILE: EL CASO DEL EMBALSE EL YESO
}

Claudia González-Muzzio ${ }^{1,2, *}$ y Claudio Rozas Vidal ${ }^{1,2}$

\section{RESUMEN}

En los últimos años ha habido un progresivo incremento en la importancia de la actividad turística como motor de desarrollo económico local en Chile y de los destinos de montaña en particular, lo cual está siendo impulsado mediante diversas políticas y programas a nivel nacional, regional y local. No obstante, estos territorios se encuentran altamente expuestos a amenazas geológicas e hidrometeorológicas, tratándose además de áreas ambientalmente sensibles, por lo que para un desarrollo sostenible de la actividad turística resulta urgente considerar una gestión integral de los riesgos asociados, contemplando a los actores institucionales, turoperadores $y$, particularmente, a los visitantes. Desde el punto de vista de la planificación territorial, parece irresponsable promover la actividad turística sin considerar, por una parte, el efecto de ella sobre el medio ambiente y por otra, las amenazas que pueden afectar el desarrollo económico y social que se busca fomentar, así como también a los propios trabajadores y a los turistas. Mediante el análisis de un ejemplo en la cordillera de la Región Metropolitana, el Embalse El Yeso, se busca explicitar las falencias y desafíos para un turismo sostenible en destinos de montaña en el país.

\section{PALABRAS CLAVE}

Turismo de montaña, Chile, Gestión de riesgos en turismo, Embalse El Yeso

DISASTER RISK MANAGEMENT IN MOUNTAIN TOURIST DESTINATIONS IN CHILE: THE CASE OF EL YESO RESERVOIR

\section{ABSTRACT}

In recent years, there has been a progressive increase in the importance of tourism as an engine of local economic development in Chile and, in particular, of mountain destinations. This is being driven by various policies and programs at national, regional and local levels. However, these territories are highly exposed to geological and hydrometeorological hazards, in addition to be considered environmentally sensitive areas. Thus, sustainable development of tourism urgently requires a comprehensive management of risks associated to mountain activities, and considering institutional actors, tour operators, and, particularly, visitors. From a regional planning view, it seems irresponsible to promote tourism activity without considering, on the one hand, the effect of it on the environment and, on the other, the hazards that may affect the economic and social development that is being promoted as well as the workers themselves and especially tourists. By examining El Yeso reservoir case study in the mountain range of the Metropolitan Region, this paper explains the limitations and challenges for a sustainable tourism in mountain destinations in the country.

\section{KEYWORDS}

Mountain tourism, Chile, Disaster risk reduction in tourism, El Yeso Reservoir

1. Ámbito Consultores, Santiago, Chile.

2. GRID Chile, Santiago, Chile.

*Autor de correspondencia: claudia.gonzalez@ambito.cl

\section{RECIBIDO}

14 de enero de 2019

\section{ACEPTADO}

28 de febrero de 2019

\section{PUBLICADO}

1 de enero de 2020

\section{Formato cita}

Recomendada (APA): González-Muzzio, C. \& Rozas Vidal, C. (2020). La Gestión de Riesgos en los Destinos Turísticos de Montaña en Chile: El Caso del Embalse El Yeso. Revista de Estudios Latinoamericanos sobre Reducción del Riesgo de Desastres REDER, 4(1), pp.1-20.

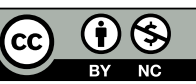

Todos los artículos publicados en REDER siguen una política de Acceso Abierto y se respaldan en una Licencia CreativeCommons Atribución-NoComercial 4.0 Internacional.

\section{Revista de Estudios}

Latinoamericanos sobre Reducción del Riesgo de Desastres (REDER)

Diseño: Lupe Bezzina Tipografia: Hospital 


\section{INTRODUCCIÓN}

Este trabajo, de carácter exploratorio, busca reflexionar respecto de la necesidad urgente de incorporar la gestión de riesgos en el ámbito del turismo de montaña, a la par de su impulso como actividad económica estratégica a nivel nacional. El objetivo es presentar un panorama general que da cuenta de la ausencia de una gestión de riesgos integral asociada a la actividad turística en el sector del Embalse El Yeso, en la comuna de San José de Maipo, ejemplificando con este caso la disociación existente entre las políticas públicas que fomentan el turismo, orientadas a aumentar la cantidad de visitantes y el beneficio económico para las comunidades locales y agentes turísticos, sin contemplar los peligros que las características geológicas y climáticas de la zona conllevan en un contexto de cambio climático, poniendo en riesgo a los visitantes sin que existan las adecuadas medidas de prevención, preparación, mitigación y respuesta frente a eventuales emergencias.

Hasta ahora, gran parte del esfuerzo por gestionar riesgos en áreas de turismo de montaña en Chile se ha concentrado en destinos de invierno asociados a actividades como el ski, debido a que la propia actividad es altamente riesgosa y depende de las condiciones ambientales y técnicas del entorno como calidad y cantidad de nieve, estabilidad climática, accesibilidad en caso de accidente, etc. No obstante, una serie de otros destinos de montaña se están promocionando a nivel nacional sin una adecuada gestión.

\section{METODOLOGÍA}

El estudio consistió en la revisión de las políticas y planes asociados al turismo en Chile y en la Región Metropolitana en particular, los instrumentos de planificación territorial (IPTs) de la comuna de San José de Maipo (Plan de Desarrollo Comunal y Plan Regulador Comunal) y contenido digital de diversas agencias de turismo que ofrecen tours al Cajón del Maipo que incluyen el Embalse El Yeso. De igual modo, se revisaron las políticas generales sobre gestión de riesgos a nivel nacional y el sitio web de la Oficina Nacional de Emergencias (ONEMI) en busca de recomendaciones específicas asociadas a la actividad turística en montaña.

Por otra parte, se realizaron tres visitas a terreno entre agosto y octubre de 2018 , y se entrevistó a tres de los comerciantes presentes en el área, así como a 10 turistas que llegan al lugar en vehículos particulares, seleccionados al azar. Dichas visitas contribuyeron también a identificar elementos asociados a la gestión de riesgos al interior del área de estudio.

De igual modo, se revisaron estudios y documentos académicos respecto de los peligros geológicos e hidrometeorológicos existentes en el área, debido a la ausencia de menciones a estos peligros en los documentos de turismo y en el Plan Regulador Comunal de San José de Maipo, por encontrarse esta zona fuera del área de planificación urbana comunal.

Por último, se incluyó en la búsqueda información en prensa digital sobre accidentes ocurridos en el sector en los últimos cinco años (periodo entre 2014 y 2018).

\section{POLÍTICAS PÚBLICAS RELACIONADAS AL TURISMO DE MONTAÑA A NIVEL NACIONAL, REGIONAL Y LOCAL}

La Ley del Sistema Institucional para el Desarrollo del Turismo (Ley 20.423 del año 2010) o Ley del Turismo señala que son Zonas de Interés Turístico (ZOIT) "los territorios comunales, intercomunales o determinadas áreas dentro de estos, que tengan condiciones especiales para la atracción turística y que requieran medidas de conservación y una planificación integrada para promover las inversiones del sector privado" (Art. 13). Estas zonas tienen prioridad para la ejecución de programas y proyectos que fomenten la actividad turística y también para aquellos que ofrecen obras de infraestructura y equipamiento necesarios para dicha actividad.

La comuna de San José de Maipo corresponde a una ZOIT desde el año 2001, que abarca todo el territorio comunal (Resolución Exenta N01138 publicada el 21 de noviembre de 2001). Dado que esta ZOIT fue declarada bajo el Decreto Ley $N^{0} 1.224$ (anterior a la Ley $N^{0} 20.423$, hoy vigente), hasta el 2 de diciembre de 2019 se debe presentar la solicitud de adecuación de esta zona para cumplir con la normativa existente, que incluye la obligación de contar con un Plan de Acción. Actualmente hay un proyecto de modificación de la ZOIT de San José de Maipo que contempla un radical ajuste de sus límites, según indica la Figura 1. 


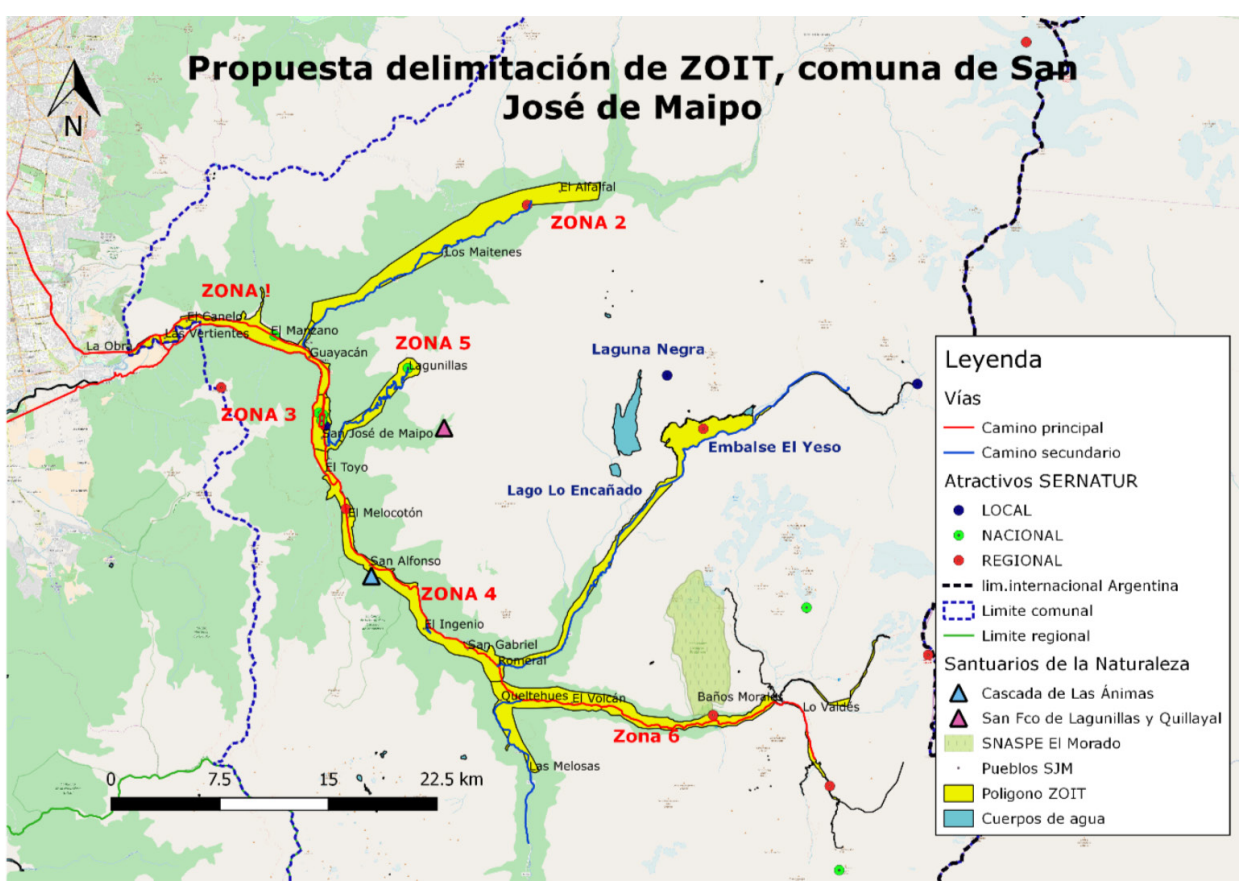

Figura 1. Propuesta de modificación de límites de la ZOIT San José de Maipo Fuente: Subsecretaría de Turismo (s/f.a.). Antecedentes ZOIT San José de Maipo

El territorio de la ZOIT San José de Maipo se encuentra destacado en variadas políticas y planes sectoriales como un activo relevante de carácter patrimonial, natural y cultural, de lo cual dan cuenta también numerosas iniciativas que buscan poner en valor sus atributos. Si bien la propuesta de ajuste de límites reconoce la Laguna Negra, el Embalse El Yeso y los Baños del Plomo como atractivos en el área de estudio, solo el embalse se encuentra dentro del polígono de redefinición de sus límites.

En cuanto a la visión construida para la ZOIT, el documento de la Subsecretaría de Turismo señala que:

"San José de Maipo en su condición de destino turístico, aspira a convertirse en un referente turístico fundamental de la Región Metropolitana, reconocido a nivel nacional e internacional, por su condición cordillerana privilegiada, con una amplia y consolidada oferta de actividades y servicios turísticos, de carácter sustentable, donde sus habitantes tengan impronta de agentes turísticos"

(Subsecretaría de Turismo, s/f.a., p.5).

Y en relación con la gestión de riesgos, las brechas identificadas en el diagnóstico incluyen la "falta [de] capacitación a la comunidad y empresarios en planes de contingencia y prevención de riesgos para atender emergencias", reconociéndolo como un problema asociado a la falta de capacidades locales. No obstante, dentro de las iniciativas priorizadas para la ZOIT no hay ninguna orientada a mejorar las capacidades relacionadas con la gestión de riesgos, ni tampoco alguna otra destinada a la reducción de riesgos asociados al turismo.

Tales brechas se identifican también en el Diagnóstico Planes Marco de Desarrollo Territorial (PMDT) Territorio Prioritario 3, cuarto informe de avance, Subterritorio 9 San José de Maipo, (Gobierno Regional Metropolitano \& Consultorías Profesionales Agraria Ltda., 2017), que da cuenta de tres problemáticas asociadas en relación al turismo aventura en el área (que considera rafting, trekking, senderismo, cabalgatas y canopy/tirolesa): conectividad vial vulnerable por existencia de una única vía (G-25) que dificulta procesos como realización de compras, evacuación frente a accidentes y el flujo expedito de los visitantes; falta de conectividad telefónica y de internet en algunos sectores (se mencionan Baños Morales y Lo Valdés, aunque tampoco hay cobertura de telefonía móvil en gran parte del área de estudio) y la peligrosidad de la vía de acceso, siendo una ruta estrecha y sin berma, compartida por vehículos grandes, pequeños y bicicletas. 
A nivel regional, el Plan de Acción Región Metropolitana Sector Turismo 2014-2018 (SERNATUR, 2014) señala que una de las dimensiones donde la región tiene un menor nivel de desempeño es el de seguridad pública y protección civil. Esta dimensión incorpora variables que miden los niveles de seguridad y la percepción que tienen de esta los ciudadanos. Sin embargo, en el documento no se establece ningún mecanismo para mejorar estos indicadores o para la gestión de los riesgos naturales o antrópicos asociados a la actividad turística en general, o de montaña, en particular.

En este contexto, cabe señalar que la Estrategia Nacional de Turismo 2012-2020 (Gobierno de Chile, s/f) define como una de las iniciativas prioritarias el desarrollo de un Plan Nacional de Seguridad Turística, cuya meta de implementación era el año 2013. No obstante, no se encontró información sobre la existencia del plan, sino únicamente respecto de una Mesa iniciada en julio de 2015 en la que participan, entre otros, la Subsecretaría de Turismo, la Oficina Nacional de Emergencia, el Servicio Nacional de Turismo, la Federación de Empresas de Turismo de Chile, la Asociación Chilena de Empresarios Turísticos, la Cámara Nacional de Comercio y Chilesertur (Subsecretaría de Turismo, s/f.b.). FEDETUR organizó en 2016 un seminario asociado a dicha iniciativa.

Según la mencionada estrategia, el Plan Nacional de Seguridad Turística se orienta principalmente a disminuir el grado de desconfianza sobre el nivel de seguridad que ofrece Chile como país receptor de turistas extranjeros. Se reconoce en este sentido la exposición del país, por su conformación geográfica y geológica, a fenómenos naturales como terremotos, maremotos, erupciones volcánicas e inundaciones y pretende definir medidas de rápida implementación que "pueden ayudar a prevenir riesgos, disminuir consecuencias e incluso mejorar la percepción de seguridad del viajero por el mero hecho de estar informado", centrándose en la entrega de información apropiada a los turistas antes y durante el viaje. Se busca además que existan sistemas que permitan auxiliar a aquellos visitantes que sufran accidentes, robos o que sean afectados por desastres, así como la comunicación adecuada hacia el extranjero sobre la evolución de eventos potencialmente catastróficos (Gobierno de Chile, s/f, p.79).

La relación entre el turismo en el área cordillerana de Santiago y la sustentabilidad ambiental es abordada en el proyecto Sistemas de Producción Sustentable para Ecosistemas de Montaña, que forma parte del Plan de Acción Santiago Andino 2005-2012 en los sitios prioritarios de conservación de la biodiversidad $\mathrm{N}^{\circ} 4$ (El Morado, donde se encuentra el sector en estudio), N ${ }^{0} 5$ y N010 de la Región Metropolitana. Si bien esta iniciativa se centró en el análisis de actividades productivas en la zona como la producción de agua, la ganadería y la minería, consideró también la existencia de la ZOIT de la comuna San José de Maipo y por ello se abordó un trabajo intersectorial mediante una mesa cuyo objetivo era elaborar un Plan de Ordenamiento Turístico para la zona.

Dicho proyecto reconoce que la actividad minera afecta el desarrollo del turismo en el área, principalmente por el polvo en suspensión producto del tránsito de camiones, lo que disminuye la visibilidad, aumenta el riesgo de accidentes y causa molestias a los visitantes (Fredericksen et al., 2010, p.46). También hace hincapié en que el potencial turístico de la zona no ha sido adecuadamente explotado, dado que hay actividades no reguladas que generan deterioro de los recursos naturales y donde el beneficio económico no llega a los actores locales.

En ese sentido, el turismo no regulado generaría en el área diversos efectos, destacando los siguientes:

- Debido a la cantidad de visitantes, algunas áreas han visto sobrepasado su 'límite de resiliencia', impidiendo la adecuada regeneración de los ecosistemas explotados.

- En muchos casos, se trata de bienes públicos, por lo que ni el Estado ni los particulares ponen especial cuidado.

- Gran parte de los turistas que llega a San José de Maipo, especialmente en verano, busca sitios para la recreación en las cercanías de cursos de agua que no tienen la infraestructura necesaria, generándose daños al lugar y su entorno.

- Existe una alta acumulación de basura generada por los visitantes, lo que además de la acción directa de estos, contribuye a la contaminación de suelos y de los cursos de agua (Fredericksen et al., 2010). 
Por su parte, la más reciente Estrategia Regional de Conservación de la Biodiversidad 20152025 (Gobierno Regional Metropolitano de Santiago \& Secretaría Regional Ministerial Metropolitana del Ministerio del Medio Ambiente, 2013), en su Lineamiento de Acción 2.3. de "apoyo a la valoración económica de la biodiversidad por actividades de turismo de intereses especiales (TIE) en áreas naturales y urbanas", considera la función que cumple la biodiversidad en la disminución del riesgo de remoción en masa. El mismo documento da cuenta de la importancia del riesgo de aluviones en la provisión de agua para la ciudad y del Embalse El Yeso como principal fuente de dicho recurso.

En cuanto al desarrollo de un turismo sustentable, el Plan Especial de Infraestructura MOP de apoyo al Turismo Sustentable a 2030, destaca que es deseable potenciar la actividad turística porque: "por un lado, contribuye a modificar la matriz económica del país y ayuda a la protección del medioambiente, al ser un sector que reúne industrias no extractivas. Por otro lado, genera trabajo, pues es intensivo en mano de obra, especialmente de mujeres y jóvenes, e incentiva el emprendimiento y la innovación. Asimismo, favorece la integración regional y fomenta la protección del patrimonio natural y cultural". Además, señala que el país se caracteriza por tener normas y reglamentos propicios para el desarrollo del turismo, una economía abierta a la inversión extranjera y un "adecuado nivel de seguridad y una infraestructura turística mejorada" (MOP et al., 2017, p.20), aunque se reconoce que existen déficit de infraestructura. Esto, como se verá más adelante, es evidente en el caso del sector del Embalse El Yeso.

Los destinos turísticos priorizados en el plan de infraestructura en la Región Metropolitana son cuatro, uno de ellos el Cajón del Maipo, considerado como destino consolidado (ver Tabla 1).

\begin{tabular}{lll} 
Provincia & Destino Priorizado & Clasificación \\
\hline Cordillera, Maipo, Talagante & Valle del Maipo & Emergente \\
\hline Cordillera & Cajón del Maipo & Consolidado \\
\hline Santiago & Santiago urbano & Consolidado \\
\hline Santiago & Centros de montaña & Consolidado \\
\hline
\end{tabular}

Tabla 1. Destinos priorizados en la Región Metropolitana y su clasificación

Fuente: Subsecretaría de Turismo en Ministerio de Obras Públicas (MOP) et al. (2017, p.23)

Las políticas y estudios señalados presentan diversos grados de implementación y niveles de aplicación, pero se aprecia que, en el ámbito de la gestión de riesgos, sustentabilidad y la relación con el cambio climático respecto de la actividad turística, no existe un tratamiento integral aún, tratándose más bien de gestiones e iniciativas aisladas.

En cuanto a la cantidad de visitantes, los datos a nivel nacional y, especialmente a nivel local, son también imprecisos, aunque muestran un significativo aumento en el flujo de turistas en los últimos años

En este ámbito, el Plan de Acción Región Metropolitana Sector Turismo 2014-2018 señala que el año 2013, 25.731 turistas llegaron a San José de Maipo, de los cuales 1.075 eran extranjeros. De igual modo, se destaca que el turismo en la Región Metropolitana (RM) correspondió al 14,5\% del PIB en dicho año. Y señala al Cajón del Maipo como 'destino priorizado', junto con Santiago Histórico y el Valle del Maipo, con una vocación asociada al turismo de naturaleza, turismo aventura, gastronomía y enoturismo y el biciturismo (SERNATUR, 2014).

Más recientemente, un estudio de la Subsecretaría de Turismo del Ministerio de Economía, Fomento y Turismo señala que durante el primer semestre de 2017 se produjo un incremento de visitantes de un $17,9 \%$ respecto del mismo período en 2016 . Los destinos más visitados consideran Santiago y sus alrededores, incluyendo el Cajón del Maipo, Isla de Maipo y otros (EMOL, 2017).

Por su parte, el Plan Especial de Infraestructura MOP de apoyo al Turismo Sustentable a 2030 reconoce que "los turistas actualmente buscan nuevas experiencias en destinos exóticos o de naturaleza prístina cuyo desarrollo turístico es incipiente" y señala que la llegada de turistas extranjeros se incrementó en un 100\% entre 2010 y 2016, constituyendo -solo en forma directael 3,3\% del PIB de 2016 (World Travel \& Tourism Council, 2017, en MOP et al., 2017, p.16 y 17). La participación de esta actividad en el PIB aumenta al 10,2\% si se consideran sus efectos indirectos. Los turistas extranjeros que llegaron a Chile en 2016 eran principalmente de América del Sur (más del $60 \%$ ), siendo los principales mercados el argentino ( $51 \%$ de las llegadas) y el brasileño (con un $8 \%$ de las llegadas y un $12 \%$ del gasto). 
En cuanto a los turistas nacionales, el estudio Turismo Interno 2016 señala que un 74\% de los hogares son 'hogares viajeros', sin embargo, se presenta una alta estacionalidad (Subsecretaría de Turismo, 2017, en MOP et al., 2017). Lo anterior, no obstante, no da cuenta de las salidas por el día, que los chilenos normalmente realizan a lugares cercanos a su residencia durante los fines de semana.

Respecto de las personas que visitan el área de estudio, se aprecia una ausencia de estadísticas confiables sobre la cantidad de turistas que llegan a San José de Maipo. Según el documento denominado Antecedentes ZOIT San José de Maipo (Subsecretaría de Turismo, s/f.a.), con base en la información de la oficina de turismo del municipio, llegarían a la zona 15.000 visitantes anuales. No obstante, a partir de lo consultado y verificado en terreno, se identificó que en un día pueden llegar más de 1.000 personas solo al área del Embalse El Yeso.

Por otro lado, un equipo de investigadores de la Universidad de Chile señala que San José de Maipo tiene una población cercana a los 15 mil habitantes, pero puede alcanzar los 120 mil, considerando la población flotante, aunque no se indican los destinos específicos. (Universidad de Chile, 2018).

\section{EL EMBALSE EL YESO EN EL CAJÓN DEL MAIPO, UNA DE LAS POSTALES DE LA REGIÓN METROPOLITANA}

El Embalse El Yeso se ubica aproximadamente a 73 km de Santiago, en el sector Romeral, comuna de San José de Maipo. El acceso al área se produce a través de la ruta G-25, por la cual se accede a todo el Cajón del Maipo desde Las Vizcachas y luego a través de la ruta G-455, a la que se ingresa en el sector de Romeral, poco después de pasar frente al Retén San Gabriel de Carabineros de Chile, el más cercano (ver Figura 2). La ruta G-455 llega a las termas o baños del Plomo, pasando por el costado sur del embalse. En dicha área, el camino presenta su perfil más angosto, alcanzando incluso menos de $5 \mathrm{~m}$ de ancho en algunos sectores.

El embalse constituye la principal reserva de agua para la población de la Región Metropolitana. Es de propiedad de Aguas Andinas, empresa sanitaria encargada de la producción y distribución de agua potable de la ciudad de Santiago y otros sectores de la región. Se terminó de construir en 1964 y tiene una capacidad de más de 250 millones de $\mathrm{m} 3$ de agua. Se ubica a $2.500 \mathrm{~m}$ s.n.m. Su entorno montañoso, caracterizado principalmente por el cerro Mesón Alto (5.257 m s.n.m.) al costado sur del embalse, el depósito del Mesón Alto al oeste y el cerro Punta Negra, al norte (4.127 m s.n.m.), junto con el cuerpo de agua del embalse, conforman un paisaje de singular belleza que lo han convertido en un atractivo turístico para muchos visitantes nacionales y extranjeros (ver Figura 3 y 4). Está considerado como atractivo en la categoría 'ríos y lagunas'.

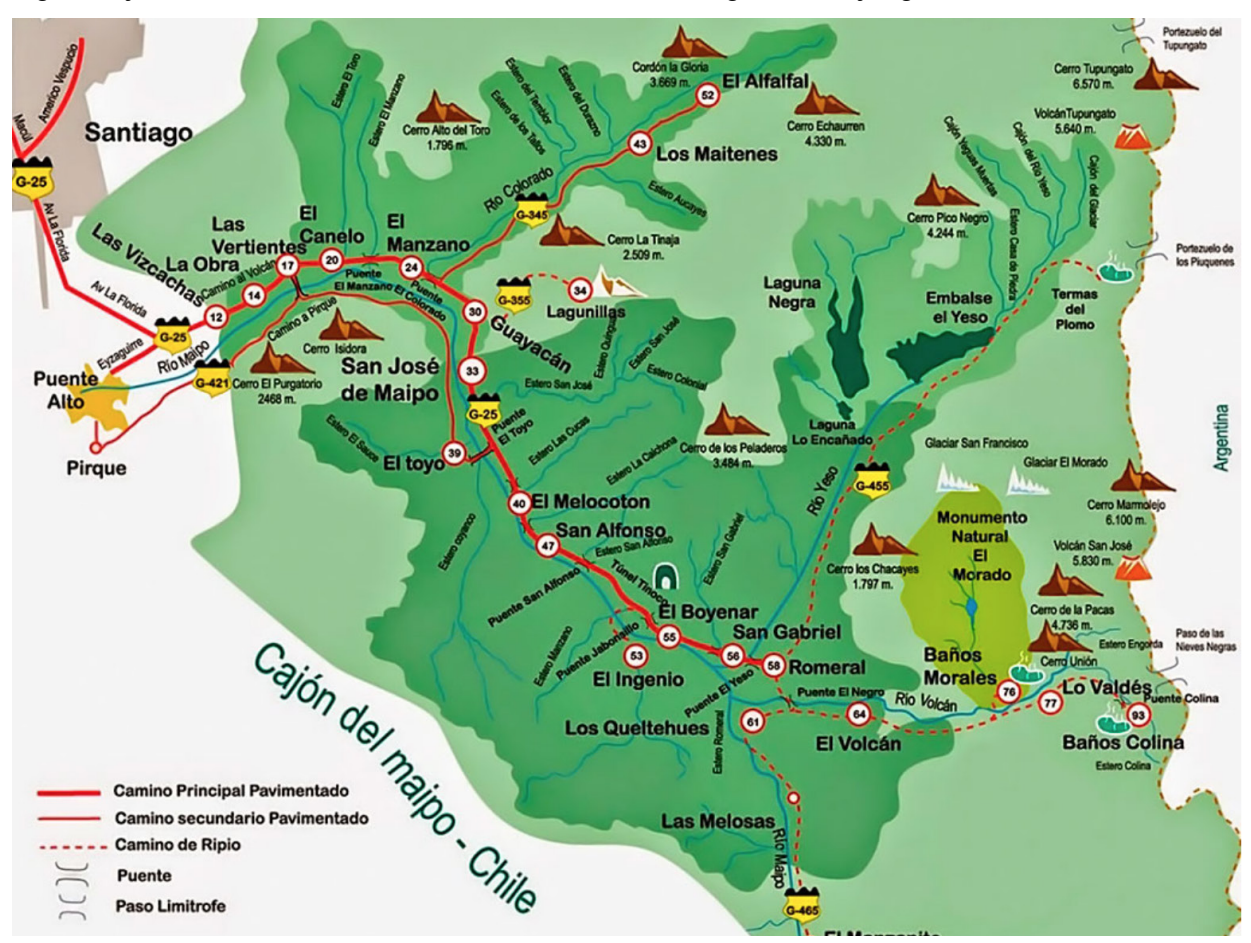

Figura 2. Embalse El Yeso en la comuna de San José de Maipo (mapa turístico)

Fuente: Cajóndelmaipo.cl (s/f). Disponible en: http://www.cajondelmaipo.com/sites/default/files/pdf/mapa_cajon_del_maipo.pdf Nota: El norte se ubica hacia arriba de la figura 


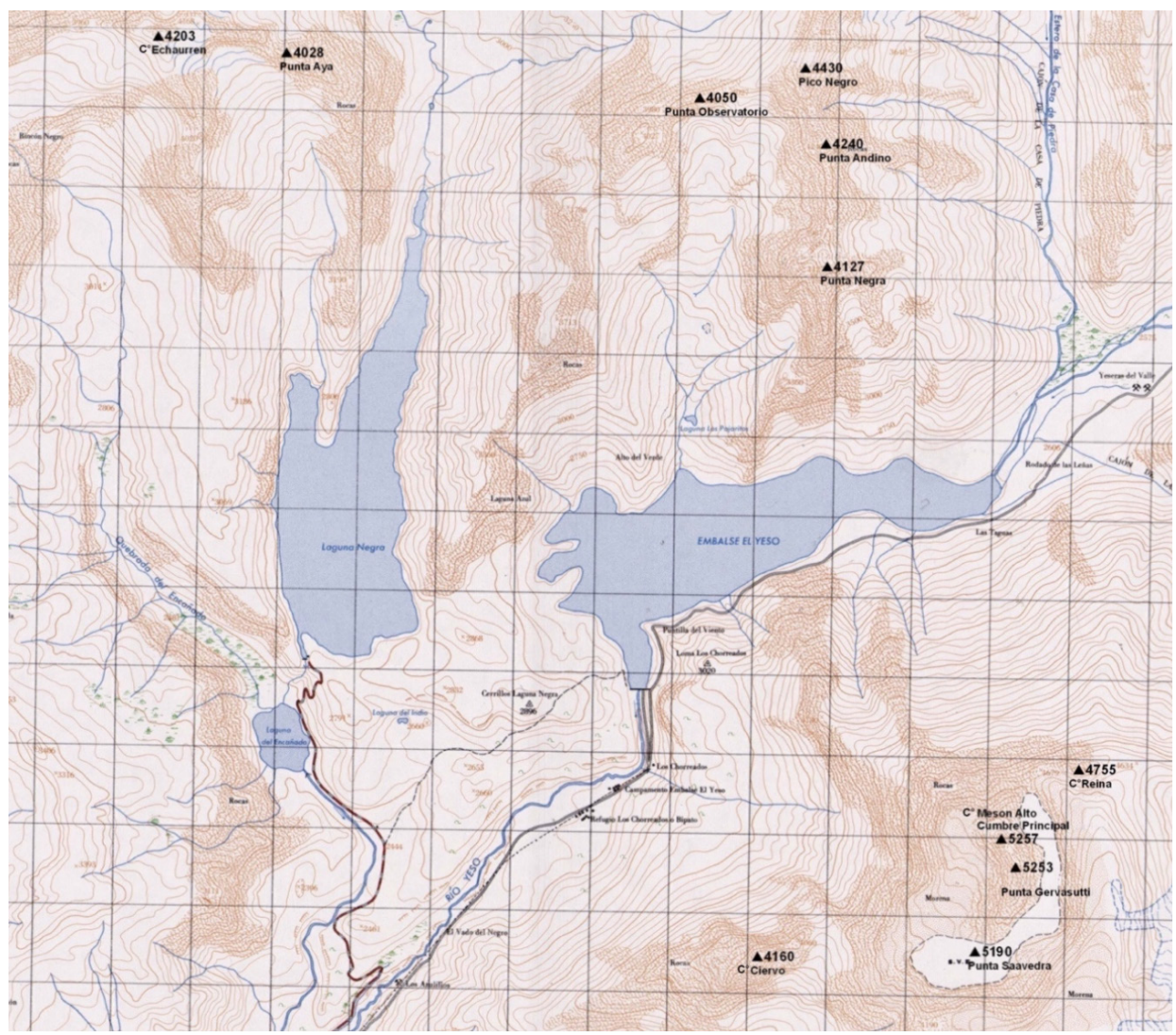

Figura 3. Cumbres relevantes en el área del embalse, sobre carta IGM Embalse El Yeso

Fuente: Perros Alpinos. Carta Embalse El Yeso versión andinista. Disponible en: http://www.perrosalpinos.cl/Nomenclatura/ Mapas/E-068\%20-\%20Embalse\%20El\%20Yeso.jpg

Nota: Grilla cada $1 \mathrm{~km}$ y norte hacia arriba de la figura

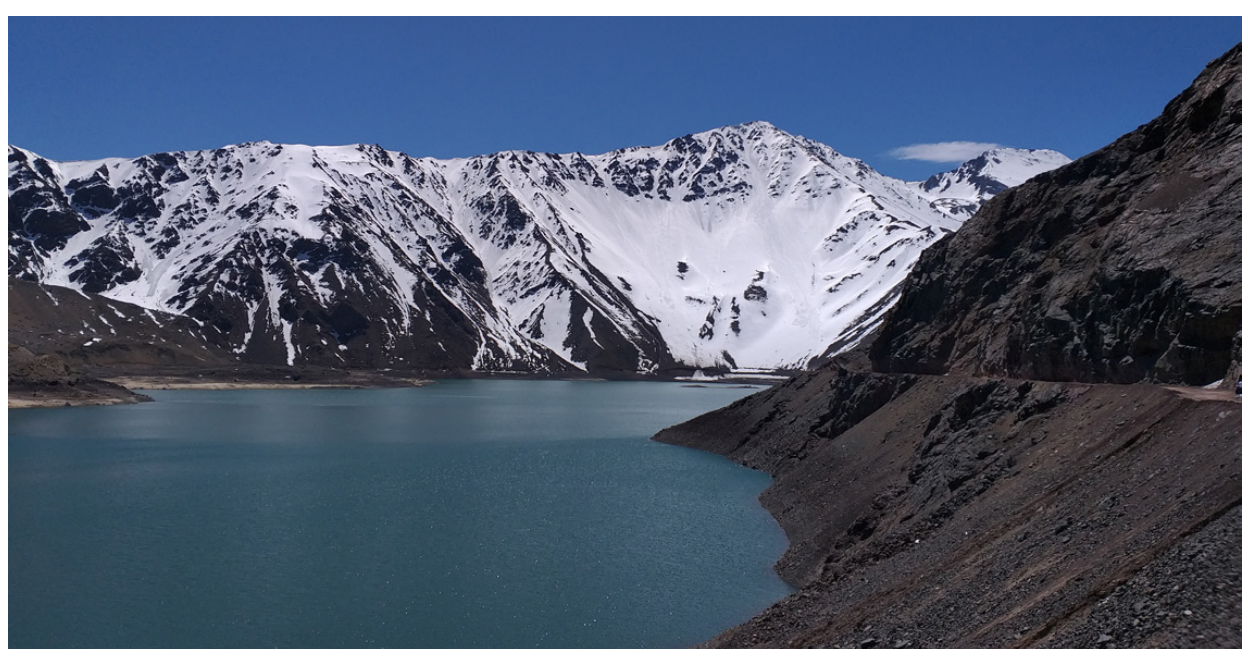

Figura 4. Embalse El Yeso, octubre 2018

Fuente: Autores, 2018

En el año 2015, la empresa AES Gener realizó la pavimentación de los primeros 4 km de la ruta G-455 (AES Gener, 2015), mientras que el Ministerio de Obras Públicas (MOP) pavimentó

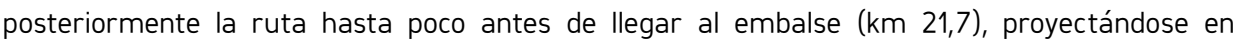
el mediano plazo un estudio de prefactibilidad para la Ruta escénica desde el Embalse el Yeso hasta los baños del Plomo y desde allí al paso Piuquenes, ello en el marco del Plan Especial de Infraestructura MOP de Apoyo al Turismo Sustentable a 2030 (MOP et al., 2017).

En el área de estudio, se considera también la construcción de un 'centro de información y servicios turísticos Embalse El Yeso', en el mediano plazo, incluyendo las etapas de diseño y ejecución (MOP et al., 2017).

En la actualidad no existe infraestructura apropiada para el desarrollo de una actividad turística cada vez más masiva, por lo que en ocasiones se satura el espacio disponible para 
estacionamiento al costado sur del camino (que se encuentra en un terreno particular, por lo que se cobra una tarifa de CLP\$4.000 por vehículo) (ver Figura 5). Este predio, donde además hay algunas construcciones que estuvieron abandonadas por años, se encontraba cerrado en octubre de 2018, para prepararlo como set para la realización de un 'reality extremo', según señalaron comerciantes en el sector del embalse. Por lo anterior, los vehículos estacionan directamente en el costado del camino, ocupando parte de la calzada tanto antes del embalse como en el área situada en el costado sur de este, disminuyendo el espacio disponible para el paso de vehículos, a pesar de la prohibición que existe de estacionar o detenerse en dicho tramo (ver Figura 6).
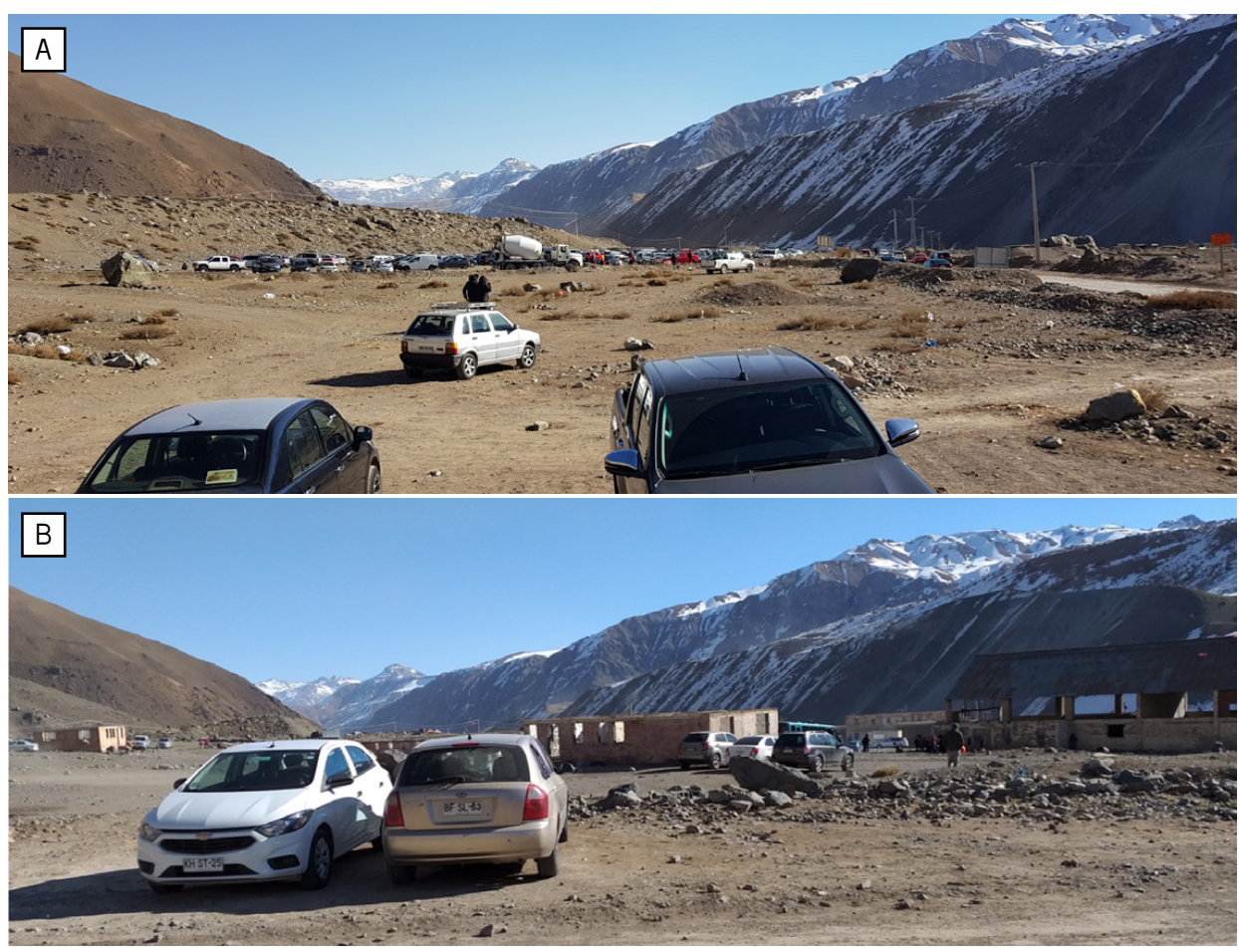

Figura 5. Terreno particular utilizado como estacionamiento Fuente: Autores, 2018

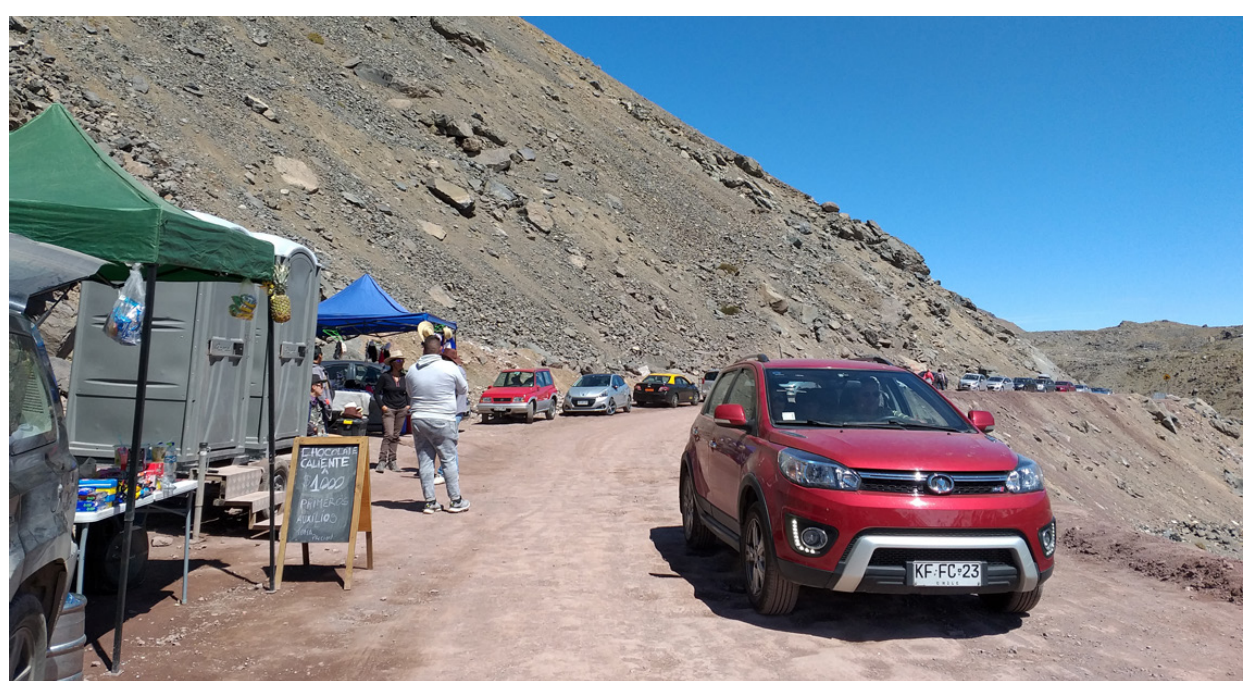

Figura 6. Vehículos y sectores con comercio temporal en el borde de la calzada adyacente a ladera, al costado sur del embalse Fuente: Autores, 2018

En los últimos años, especialmente durante los fines de semana, se instalan puestos transitorios (foodtrucks) y otros de venta informal con autorización del municipio, que se emplazan tanto en las cercanías como en el costado del embalse. Algunos de estos comerciantes instalan también baños químicos para su uso por parte del público (con un costo de CLP\$500). Según lo indicado por ellos, el municipio entrega un total de diez permisos de uso temporal del espacio público (en sectores adyacentes a la calzada vehicular). No hay agua potable y tampoco iluminación pública (ver Figura 7). 
En caso de nevadas, algunos de los vendedores se instalan cerca del retén de Carabineros de San Gabriel para ofrecer arriendo de cadenas, mientras que la venta informal de provisiones en torno al embalse disminuye por la inadecuada accesibilidad.

La llegada de visitantes se produce en vehículos de turismo que proveen tour por el día y que incluyen también otros atractivos de la comuna (en minibuses) o bien en vehículos privados, taxis e incluso en bicicletas de montaña, en menor medida. Todos ellos compiten por ubicarse lo más cerca posible del espejo de agua del embalse.
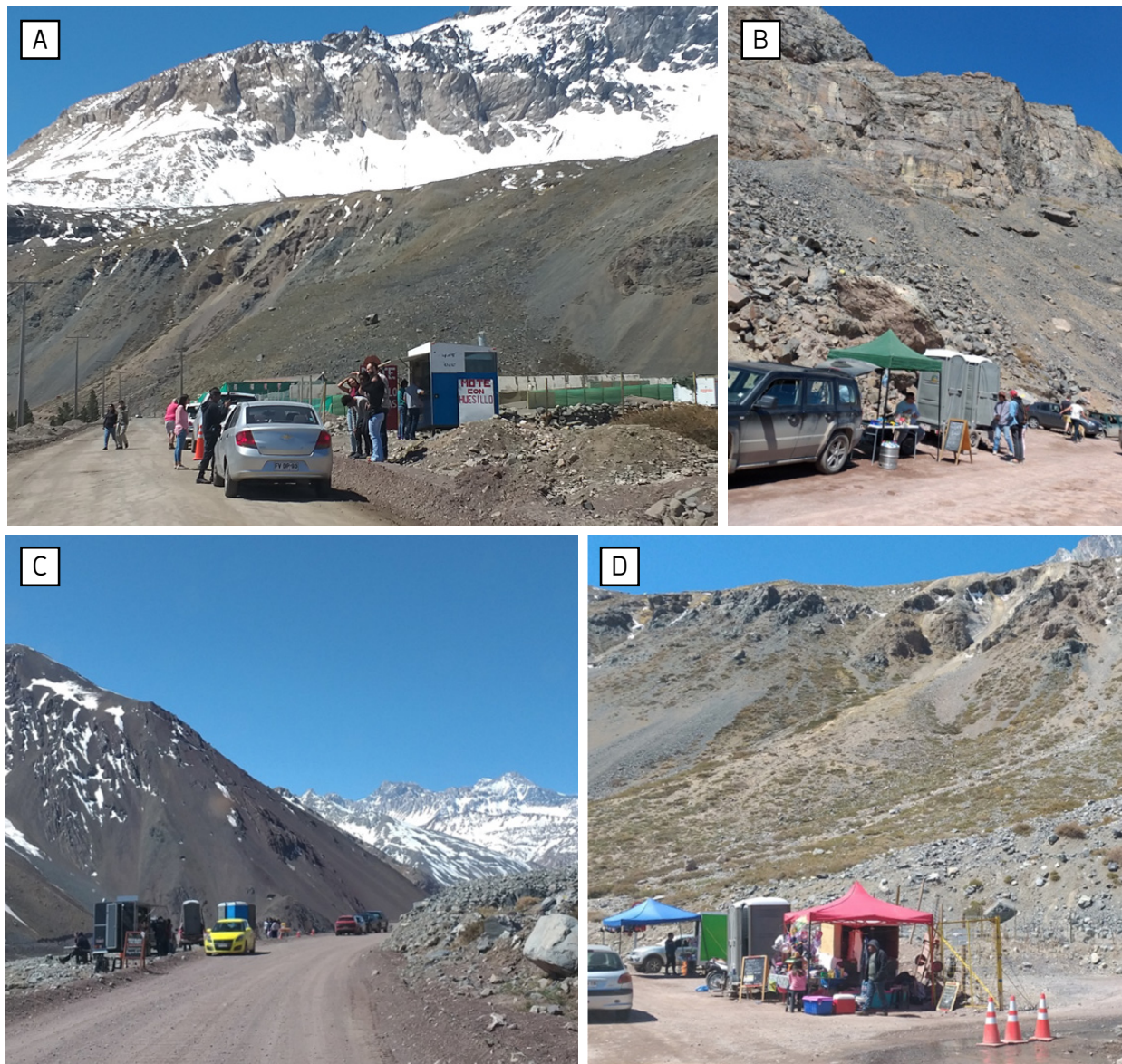

Figura 7. Puestos de venta, baños químicos y carros de venta de comida en distintos sectores del área de estudio Fuente: Autores, 2018

Si bien es posible el ingreso al sector en vehículo, pues la ruta continúa más allá del embalse hasta los Baños del Plomo, el acceso vehicular se ve condicionado por el estado de la ruta, la presencia de nieve, derrumbes y por la propia intensidad de la actividad turística.

Así, en algunos casos, los visitantes se acercan al área del embalse a pie, en caminatas de una hora y más -sumando ida y regreso- (ver Figura 8). Cuando ingresan vehículos y estacionan en la ruta (a pesar de estar prohibido), estos comparten la calzada con visitantes a pie, así como con automóviles y minibuses que buscan seguir circulando por el camino hacia o desde la zona más cordillerana, con el consiguiente peligro para los transeúntes y la dificultad de realizar una evacuación masiva en caso de requerirse e impidiendo también el acceso a vehículos de emergencia incluso ante un evento puntual (Figura 9 y 10).
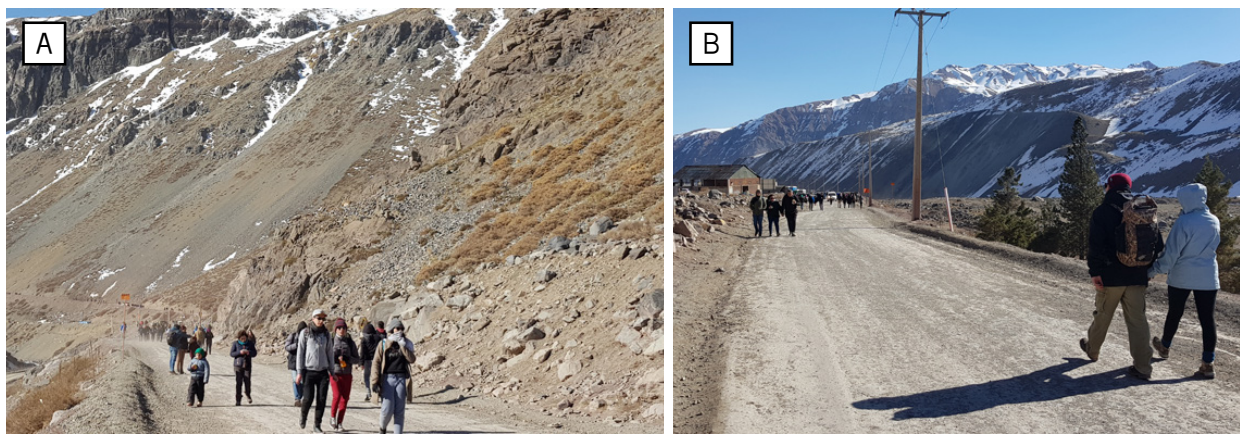

Figura 8. Turistas regresando desde el embalse o acercándose a este, agosto 2018, 16:15 horas Fuente: Autores, 2018 


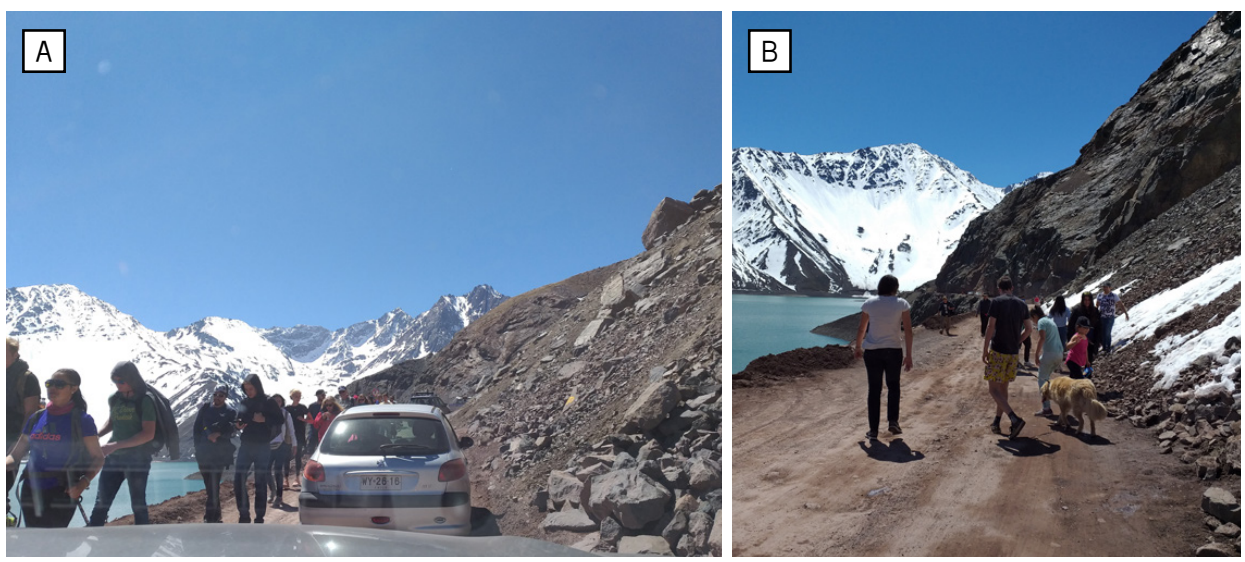

Figura 9. Paso de turistas a pie y en vehículo en la misma vía, sin información ingreso con mascotas al área Fuente: Autores, 2018

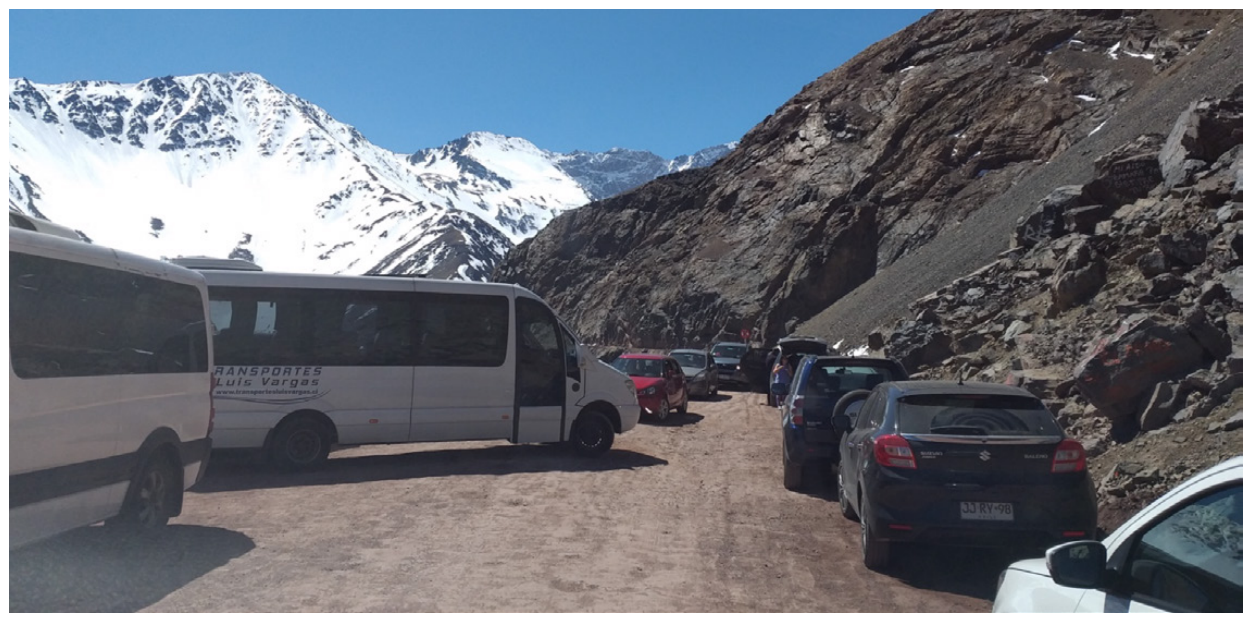

Figura 10. Colapso en la ruta por presencia de vehículos privados y de turismo estacionados en la ruta Fuente: Autores, 2018

\section{LOS PELIGROS PRESENTES EN EL SECTOR DEL EMBALSE EL YESO}

El área del Embalse El Yeso se ubica en la zona de precipitaciones invernales en los subtrópicos de alta insolación del hemisferio Sur y en la zona de transición entre el clima semiárido y semihúmedo (Bustamante et al., 2010, en Arriagada et al., 2015). El clima en la subcuenca El Yeso ha sido catalogado como mediterráneo con estación seca prolongada según la clasificación de Köppen, caracterizado por lluvias invernales que se concentran entre mayo y agosto, y una estación seca prolongada de 7 a 8 meses hasta los $1.100 \mathrm{~m}$ de altitud. El clima va variando conforme la altura, con predominio de bajas temperaturas y abundancia de precipitaciones sólidas especialmente a partir de los 3.000 de altitud. La precipitación media anual es cercana a los 600 mm (Tabla 2).

\begin{tabular}{|c|c|c|c|c|c|c|c|c|c|c|c|c|c|}
\hline Mes & Ene & Feb & Mar & $A b r$ & May & Jun & Jul & Ago & Sep & Oct & Nov & Dic & Media \\
\hline Pp mm & 6,2 & 8,2 & 9,8 & 37,7 & 81,3 & 143,8 & 128,2 & 92,5 & 44,0 & 21,2 & 19,1 & 7,9 & 599,8 \\
\hline TOC Máx. & 20,7 & 20,8 & 19,2 & 15,3 & 10,7 & 6,8 & 5,8 & 7,1 & 9,5 & 13,1 & 16,1 & 19,1 & 13,7 \\
\hline TC Mín. & 8,7 & 8,8 & 7,8 & 5,1 & 2,1 & $-0,7$ & $-1,9$ & $-1,6$ & $-0,1$ & 2,4 & 5,1 & 7,4 & 3,6 \\
\hline Oscilación & 12,0 & 11,9 & 11,4 & 10,2 & 8,6 & 7,5 & 7,7 & 8,7 & 9,6 & 10,7 & 11,1 & 11,7 & 10,1 \\
\hline
\end{tabular}

Tabla 2. Precipitaciones y temperatura máxima-mínima mensual de la estación meteorológica Embalse El Yeso (1962-2015) Fuente: DGA en Arriagada et al., 2015

El aumento de altura produce cambios en la presión atmosférica, así como en la "predominancia y magnitud de los vientos, que es intenso durante todo el día en las altas cumbres y portezuelos, mientras que a primeras horas de la tarde adquiere intensidad en la zona encajonada de los valles". Las temperaturas mayores están asociadas a los cauces de los ríos mientras que las más frías se asocian a las cumbres de los cerros (Arriagada et al., 2015, p.8). 
La sensación térmica puede variar de un momento a otro, asociada a los cambios en la velocidad y procedencia del viento. Y de igual modo, puede variar bruscamente el tiempo de despejado a nublado, con o sin precipitaciones.

En cuanto a los efectos observados del cambio climático, se tiene que las variaciones de los glaciares en la zona central del país han revelado un proceso de desglaciación durante el siglo XX (Fredricksen et al., 2010; García et al., 2014), donde la mayoría de los glaciares de la región presentan retroceso, pérdida de masa y adelgazamiento de la superficie. Algunos de los glaciares de menor tamaño podrían desaparecer si se mantuvieran o aceleraran las tendencias de retroceso (Fredricksen el al., 2010, p.41). Esta desglaciación produce aumentos inusuales en los cauces de ríos durante los meses estivales (Pizarro-Tapia et al., 2011).

Pizarro-Tapia y colaboradores observaron que para las cuencas altas del Maipo y río Colorado es posible que las precipitaciones estivales sigan aumentando a través del tiempo, producto de la variabilidad climática observada en esta zona, cuestión que se ha manifestado durante las últimas décadas, aunque en períodos secos los caudales aumentan notoriamente producto del aporte de agua del derretimiento glaciar (Pizarro-Tapia et al., 2011).

En cuanto a su geología, el área de estudio corresponde principalmente a la Formación Abanico, una secuencia de rocas volcánicas, principalmente andesíticas y riolíticas, con intercalaciones de rocas sedimentarias continentales que incluye la presencia de depósitos lagunares como la Laguna Negra y e intrusiones rocosas como como el Plutón La Gloria, cercano a dicha laguna y uno de menor tamaño en torno al cerro Mesón Alto. Las rocas de la Formación Abanico se encuentran deformadas por un sistema de fallas y pliegues denominadas Falla Chacalles - Yesillo y Falla Laguna Negra.

Hacia el oriente hay otra unidad rocosa, la Formación Colimapu, que corresponde a rocas sedimentarias y está constituida por areniscas estratificadas, lutitas y calizas.

Asimismo, hay una serie de depósitos no consolidados, incluyendo principalmente depósitos coluviales, que "forman escombros de falda en las laderas de los cerros, pero también forman abanicos de fuerte pendiente", compuestos por fragmentos de rocas meteorizadas por efecto mecánico o químico, y depósitos aluviales, que forman abanicos a la salida de quebradas, de menores pendientes que los coluviales y que están formados por clastos tamaño bloque a grava, además de arenas, limos y arcillas (Bustamante et al., 2010, en Arriagada et al., 2015, p.20).

Arriagada et al. (2015) señalan que la tasa de erosión es alta producto del clima, por lo que las laderas se presentan mayormente como roca desnuda o cubiertas de coluvios. Lo anterior, sumado a la presencia eventual de agua o nieve puede generar deslizamientos, caídas de rocas o derrumbes. También producto del tipo de suelo y la escasa presencia de vegetación, las precipitaciones intensas o derretimientos de nieve pueden causar la saturación del suelo, desencadenando a su vez deslizamientos de tierra y flujos de barro o detritos.

De este modo, en términos hidrometeorológicos, los peligros para los visitantes se asocian al aumento brusco de caudales producto de deshielos, así como cambios rápidos de temperatura, velocidad y dirección del viento y la presencia de precipitaciones líquidas o sólidas. Las precipitaciones estivales, que normalmente se producen con isotermas mayores que en invierno, pueden a su vez causar aludes o aluviones, o gatillar remociones en masa, lo cual puede también ocurrir en caso de precipitaciones invernales de alta intensidad en un corto período de tiempo, como ha sucedido en los últimos años (ver listado de eventos más adelante).

En cuanto a los peligros geológicos, el área puede verse afectada por sismos de subducción o bien asociados a fallas presentes en la zona, que pueden también provocar caídas de rocas o deslizamientos de tierra.

De igual modo, la zona se ubica en el área de influencia de volcanes activos como el Tupungatito y el San José, que en caso de hacer erupción podrían ocasionar también sismos, derretir hielos en áreas aledañas, generar lahares y/o cubrir con cenizas el área, entre otros efectos.

En síntesis, debido a las características de la zona, el peligro más relevante en el área de estudio corresponde "a distintos tipos de remociones en masa, de los cuales se aprecia abundante evidencia, junto a peligros asociados a inundaciones (por el aumento de los caudales, ya sea por remociones, lluvias intensas o rápido derretimiento de nieve y hielo)", incluyendo caída de rocas, de ocurrencia frecuente (Arriagada et al., 2015, p.66) (ver Figura 11). 
Además de los efectos directos que estos peligros pueden tener sobre la actividad turística, es necesario considerar el propio embalse, dada su condición de infraestructura estratégica para la ciudad de Santiago, pues "cualquier factor que afecte al río o sus tributarios aguas arriba, trae consecuencias aguas abajo en el embalse" (Arriagada et al., 2015, p.67). Asimismo, un aumento de sedimentos producto de inundaciones, lahares o remociones en masa, pondría en riesgo el suministro de agua potable para la ciudad de Santiago.

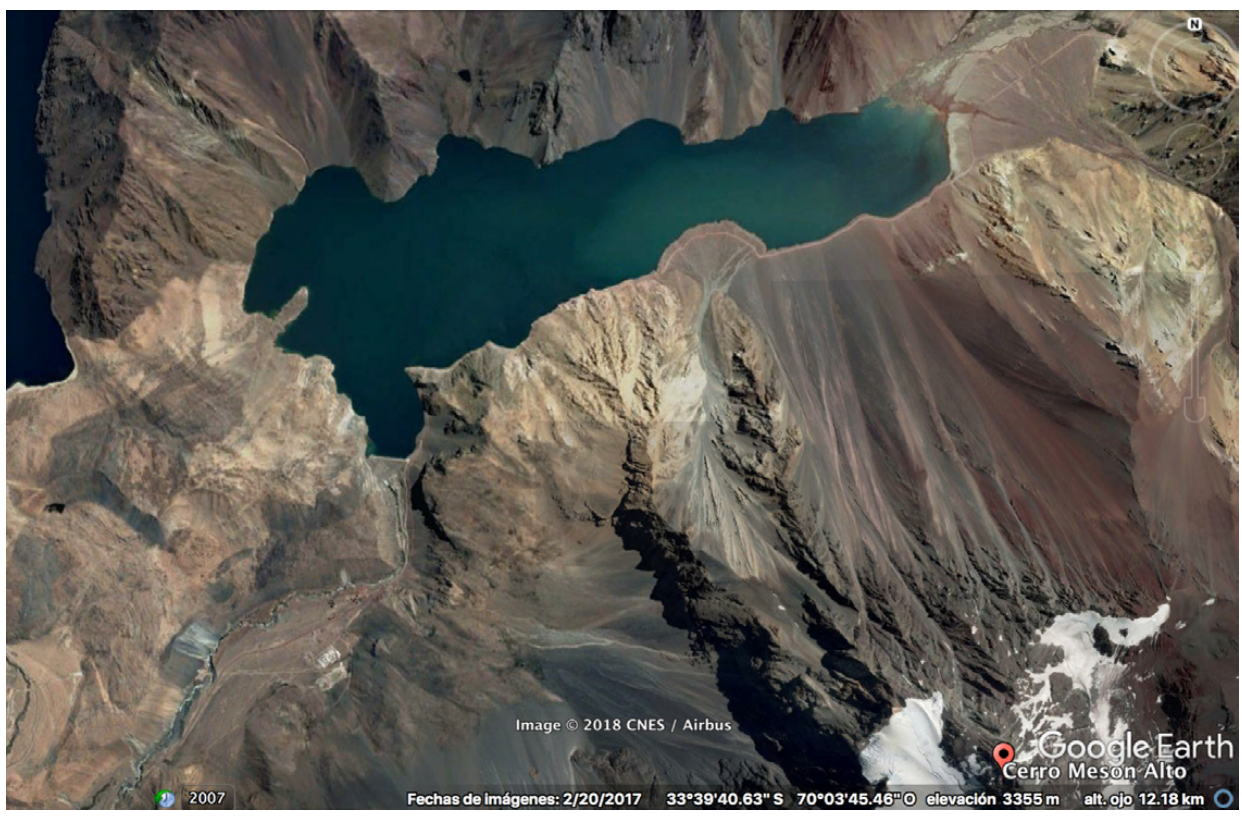

Figura 11. Sector del Embalse del Yeso y cumbre del cerro Mesón Alto, con evidencia de deslizamientos y remociones en masa Fuente: Google Earth, 2018

De acuerdo con el catastro de desastres asociados a peligros geológicos realizado por el Servicio Nacional de Geología y Minería -SERNAGEOMIN- (2017), los principales eventos ocurridos en la zona del Cajón del Maipo son:

- Marzo de 1980: Aluviones en los ríos Mapocho, Maipo, Yeso y Colorado, generan cortes en camino y daños en estructuras.

- Julio de 1981: Flujo de detritos en la bocatoma de la planta Queltehues de Chilectra, ocasionaron 2 muertes y daños en la estructura de captación.

- 27 de junio de 1982: Desbordes del río Mapocho y del Zanjón de la Aguada, además de seis rodados de nieve y tierra en Las Vizcachas y Romeral, en el Cajón del Maipo.

- 29 de noviembre de 1987: Deslizamiento de rocas y flujo de detritos en el río Colorado, que afectó a campamentos del proyecto Central Hidroeléctrica Alfalfal, dejando 41 muertos y/o desaparecidos, daños por 12 millones de dólares en infraestructura energética y puentes.

- Septiembre de 1991: Aluvión en la quebrada Las Amarillas bloquea del camino.

- 23 y 24 de abril de 1997: Flujos de detritos y barro en la quebrada Las Amarillas, ocasionó problemas en provisión de agua en Región Metropolitana.

- 8 de octubre de 1997: Deslizamiento activo en el Cerro Divisadero, en San José de Maipo, se reactiva además el 8 de septiembre de 1999 y el 14 de junio de 2000

- 12 y 13 de junio de 2012: Remociones en masa por lluvias en el sector de Avenida El Carmen, en San José de Maipo.

- 18 de junio de 2012: Caída de rocas en el sector El Ingenio, corte de la ruta G-25.

- 21 de enero y 8 de febrero de 2013: Flujos de detritos en el Cajón del Maipo, por 2 días cada vez, bloquearon varios caminos y afectaron el suministro de agua potable al Gran Santiago. 
A ellos se suman otros eventos, gatillados por peligros geológicos, hidrometeorológicos o accidentes, entre los que se cuentan los siguientes:

- 17 de julio de 2016, una persona fallece al caer al Embalse El Yeso, mientras practicaba ciclismo de montaña. (Puente Alto Al día, 2016).

- Aluviones ocurridos en febrero de 2017 dejaron tres desaparecidos y mil aislados entre San Alfonso y el sector del embalse, daños en puentes y caminos. Afectó también la provisión de agua potable del Gran Santiago por varios días (Chilevisión, 2017).

- El 5 de febrero de 2018, un desprendimiento de rocas afectó la ruta entre el Embalse El Yeso y las Termas del Plomo, quedando cerca de 70 personas aisladas, que fueron evacuadas con helicóptero. (La Tercera, 2018a).

- $\quad$ El 19 de septiembre de 2018, Carabineros debió rescatar a familia cuyo vehículo quedó atrapado en el camino cerca del embalse. (La Tercera, 2018b).

Finalmente, cabe señalar que comerciantes entrevistados en terreno comentaron de caída de vehículo en el sector del embalse en el mes de septiembre de 2018, así como también se observó en octubre vehículos atrapados en áreas de vegas ubicadas en el camino a los Baños del Plomo donde la nieve se había derretido recientemente y en sectores que forman parte del embalse y se encontraban sin agua debido al bajo nivel que presentaba en ese momento (Figura 12).

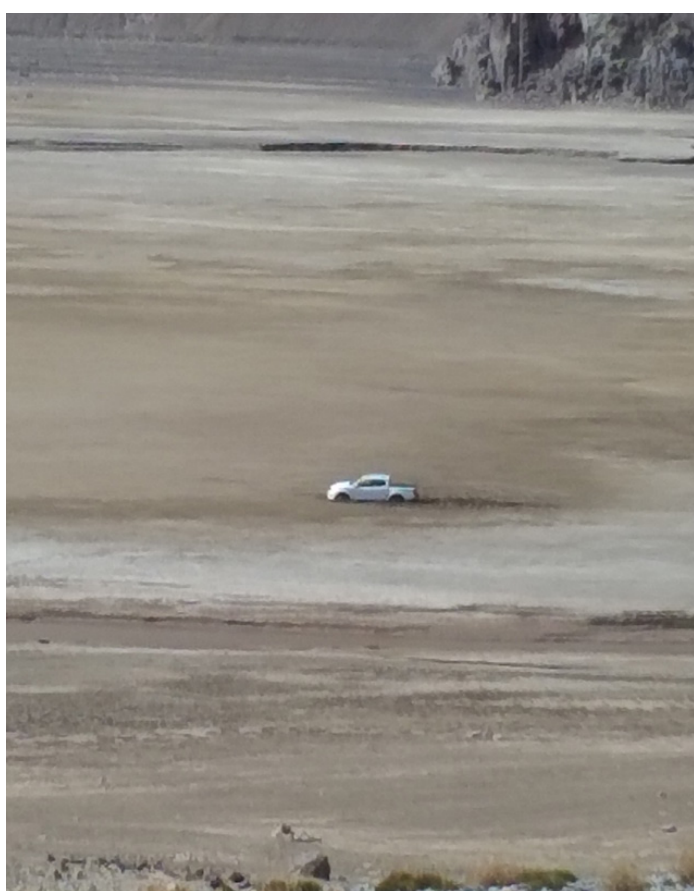

Figura 12. Camioneta atrapada en fango correspondiente al fondo del embalse en área que se encuentra sin agua

Fuente: Autores, 2018

\section{LA GESTIÓN DE RIESGOS EN EL EMBALSE EL YESO Y SU ENTORNO}

La Guía para la Implementación de Normas de Calidad Turística Turismo Aventura del Servicio Nacional de Turismo (SERNATUR) (s/f) contiene extensa y detallada información para la evaluación de riesgos y preparación de planes y protocolos de emergencia, y está destinada a las agencias turoperadoras, particularmente aquellas de turismo aventura.

Esta guía se enmarca en lo establecido en la Ley Nº 20.423 (Ley de Turismo) y en el Reglamento del Sistema de Clasificación, Calidad y Seguridad de los Prestadores de Servicios Turísticos (aprobado mediante Decreto 222/2010 y actualizado en 2018), señalando al respecto del registro de prestadores de turismo que la inscripción es obligatoria para los prestadores de servicios de alojamiento turístico y los de servicios de turismo aventura. En el capítulo IV, el Reglamento establece estándares de seguridad para la prestación de Servicios de Turismo Aventura que incluye, entre otros requisitos, la obligación de contar con una ficha técnica de la actividad que se realiza, una Ficha de inscripción y de aceptación del riesgo de la actividad por parte del cliente, un 
Plan de Prevención y Manejo de Riesgos y un Plan de Respuesta a las Emergencias, además de estándares y exigencias sobre equipamiento y un plan de mantenimiento de los equipos (Ministerio de Economía, Fomento y Turismo: Subsecretaría de Turismo, 2019).

De lo anterior, se desprende que aquellas compañías turísticas que ofrecen servicios de tour hacia el área del embalse deben cumplir con estos requisitos, dado el tipo de actividad que realizan. No obstante, respecto de aquellos visitantes que llegan a la zona de manera independiente no existe ninguna obligación.

Por lo anterior, son sumamente relevantes las medidas que puedan establecerse a través de otros medios.

En este sentido, se realizó una revisión en sitios web que mencionan el Embalse El Yeso como atractivo turístico y las recomendaciones para los visitantes, registrándose en el portal de promoción turística 'Cajondelmaipo.com' breve información sobre el embalse, donde se advierte que la vía es angosta y presenta escaso tránsito vehicular, advirtiéndose manejar con precaución y dando cuenta de la falta de señalización. El mismo sitio recomienda, respecto de los Baños del Plomo, visitar el lugar preferentemente en primavera y verano, tener precaución con el clima y llevar ropa abrigada y elementos de seguridad, en caso de que se vaya a acampar a la zona.

Por otro lado, la Oficina Nacional de Emergencias (OMEMI) entrega permanentemente alertas en relación con situaciones de potencial peligro en el área cordillerana que son accesibles a toda la población. La Municipalidad de San José de Maipo, por su parte, comparte la información proporcionada por ONEMI por medio de sus redes sociales. No obstante, en muchos casos, los turistas no buscan información sobre peligros antes de visitar un determinado sitio.

Cabe señalar que el 5 de septiembre de 2018, se publicó una resolución de la Secretaría Regional Ministerial (SEREMI) de la Región Metropolitana del Ministerio de Transportes y Telecomunicaciones, la Resolución Exenta N5615/2018, que prohíbe la circulación de vehículos motorizados en ruta G-455 (Camino El Yeso) y Ruta G-355 (Camino Lagunillas). Esta restringe el ingreso entre abril y agosto a partir del km 21,7 en delante de la ruta $\mathrm{G}-455$ y establece horario de subida (de 6:00 a 14:00) y bajada (15:00 a 21:00) durante el resto del año para ambas rutas, exceptuándose los vehículos de emergencia, los residentes y los asociados a obras autorizadas en el sector (Aguas Andinas o la mina de yeso, por ejemplo). La restricción comenzó a regir en diciembre de 2018

Esta prohibición, según indica la mencionada resolución para el caso de la ruta G-455, surge de:

- La preocupación de la Gobernadora de la Provincia Cordillera: por presencia, cada fin de semana, de gran número de turistas que visitan el Embalse El Yeso, lo que los expone a diversos riesgos, puesto que la ruta de acceso sería inestable, estrecha y peligrosa, por lo que solicita se prohíba acceder al kilómetro 23 de la misma.

- Un informe técnico de la SEREMI Metropolitana de Obras Públicas que indica que: 17 kilómetros de la ruta G-455 están pavimentados y entre kilómetro 21,7 y 27, disminuye su ancho de la calzada, presenta cortes profundos con mayor pendiente, el camino se torna sinuoso con quebradas profundas, lo que hace un difícil tránsito. Por todo lo anterior, entre otras cosas, recomienda establecer en época invernal, por seguridad y accesibilidad, horarios de ingreso a la ruta.

- La consideración respecto a que: si bien el Embalse El Yeso constituye un sitio de atracción turística, que motiva la presencia de un gran número de vehículos en los fines de semana, principalmente en época invernal, ello debe compatibilizarse con la adopción de medidas de gestión de tránsito que permitan un acceso seguro y ordenado al lugar, teniendo presente la peligrosidad que presentan diversos sectores del camino.

Cabe hacer notar que la restricción se basa principalmente en la peligrosidad relacionada con accidentes de tránsito en la ruta o su inadecuada accesibilidad ante determinadas condiciones climáticas, pero no hay mención a otros riesgos o peligros presentes en el lugar. Además, si bien restringir el acceso en vehículo durante el invierno permite regular el flujo de visitantes, no impide a estos llegar a pie, lo que se hará en condiciones igualmente precarias y sin infraestructura adecuada para la realización de actividades turísticas. Se optó, en este caso, por restringir el acceso en lugar de mejorar las condiciones de seguridad que ofrece la vía (ensanche, mejoramiento de perfil, pavimentación de tramos restantes, etc.). 
En cuanto a medidas de gestión de riesgo que se observan en el área de estudio, ellas corresponden únicamente a señalética. Así, respecto de las amenazas, se reconoce principalmente el peligro volcánico, existiendo información general sobre comportamiento del visitante en relación con tres niveles de alerta, aunque no se señala cuál de los niveles está vigente en el momento de la visita. Además, hay letreros en distintos puntos indicando la dirección de la evacuación en caso de algún evento asociado a la actividad volcánica. También se informa del peligro de 'rodados' en la ruta hacia el embalse, pero no en el sector de mayor actividad turística, por lo que los visitantes transitan por la zona sin advertencia. Por último, se informa también respecto del riesgo de accidentes vehiculares en áreas donde ya ha existido más de un incidente, ocasionado ya sea por exceso de velocidad, el estado del camino, las circunstancias climáticas, la presencia de camiones u otras razones (ver Figura 13 y 14 ).
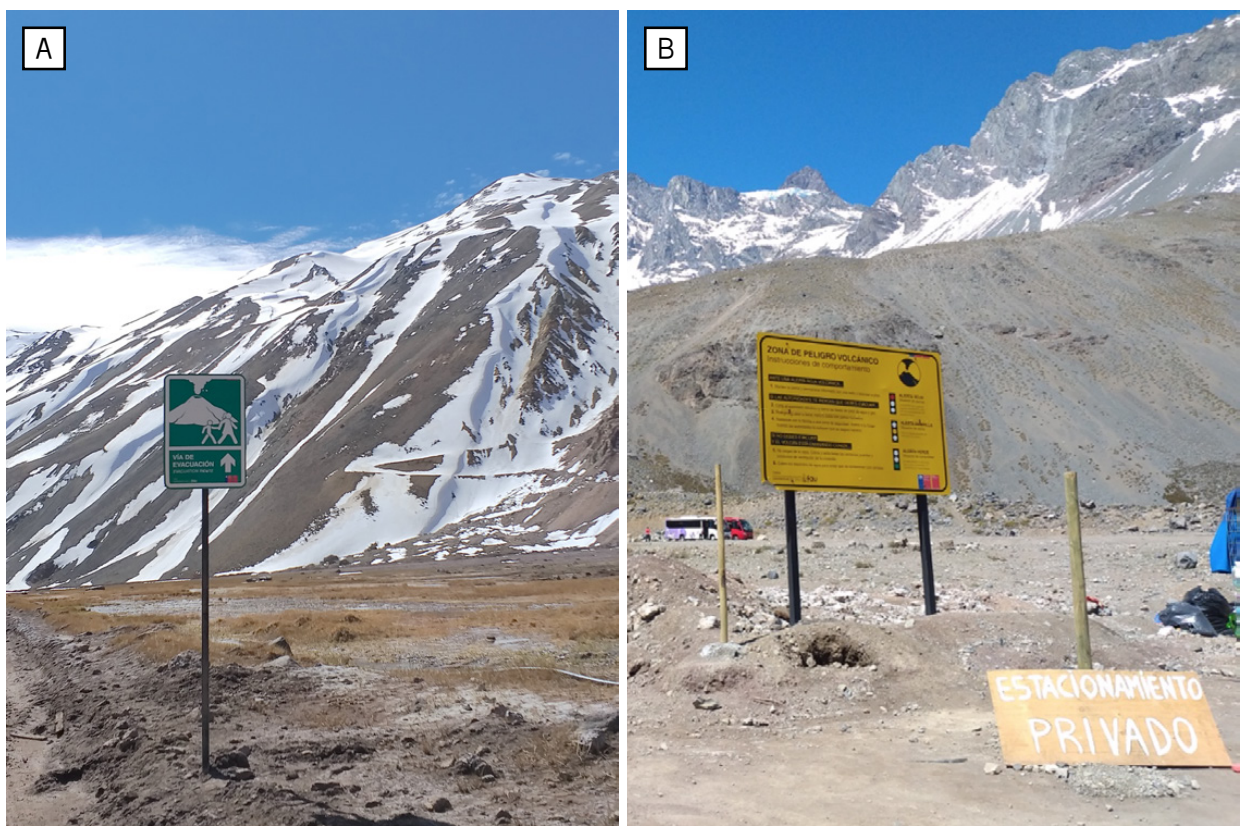

Figura 13. Señalética en la ruta sobre peligro volcánico y vía de evacuación frente a amenaza volcánica Fuente: Autores, 2018
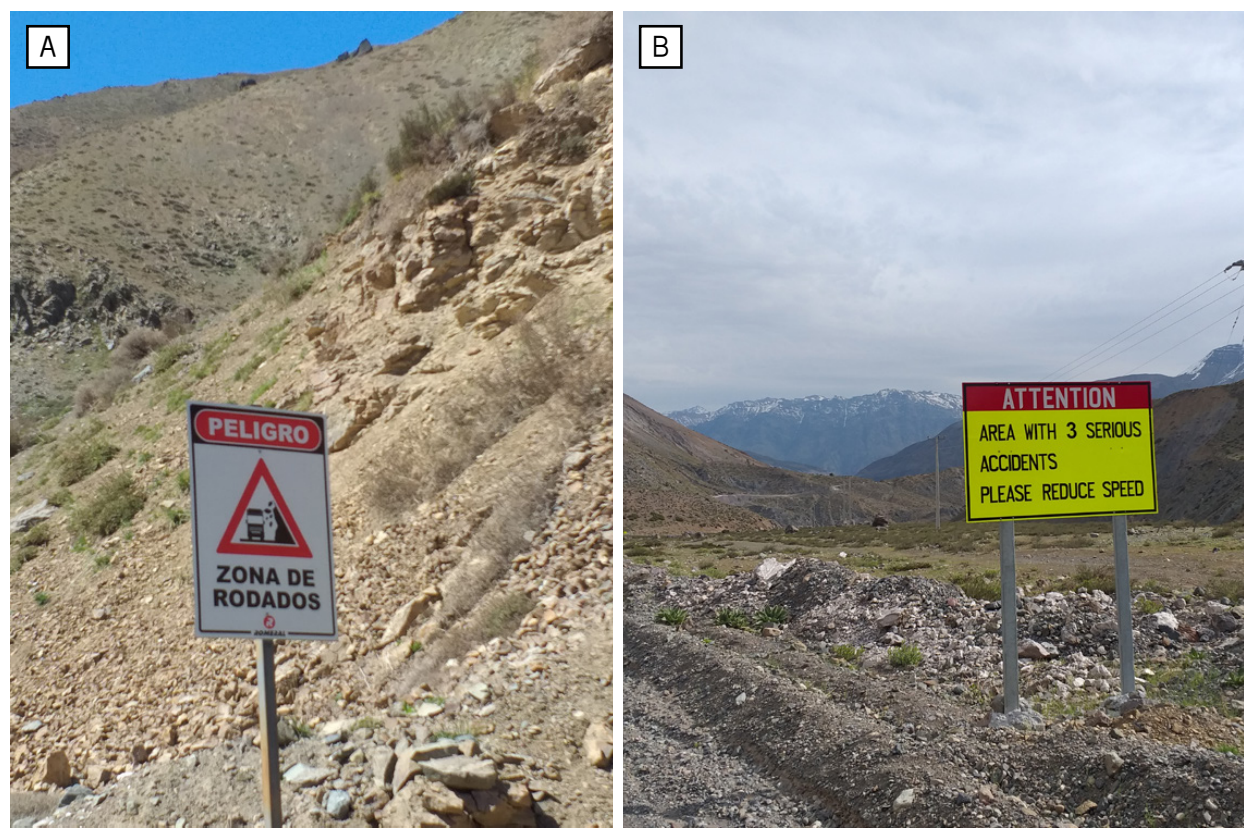

Figura 14. Señalética vial de advertencia en ruta que accede al sector del embalse Fuente: Autores, 2018 
Además, hay diversas señales de prohibición de estacionar y detenerse en el sector de la ruta G-455 que bordea el costado sur del embalse, pero ninguna mención en dicha zona sobre el peligro de remoción en masa, deslizamientos o caídas de roca (Figura 15).

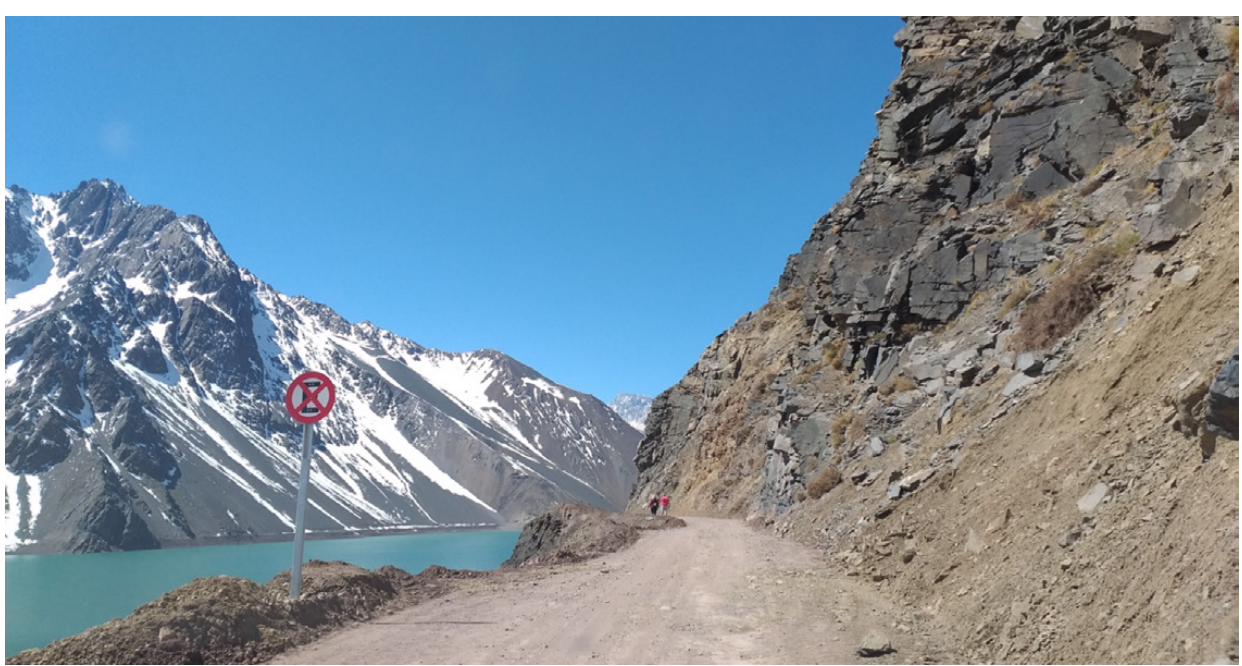

Figura 15. Señalética vial de prohibición de estacionamiento y detención en ruta G-455 bordeando embalse Fuente: Autores, 2018

Si bien quienes llegan al área en tour regulados deben contar con información puntual sobre los peligros de la actividad específica que realizarán, según lo exige la normativa vigente para el turismo aventura, quienes llegan de manera autónoma en su mayoría no están informados sobre los posibles peligros existentes en el sector. No solo aquellos asociados a accidentes vehiculares o volcanismo, sino también los constantes deslizamientos de tierra, caída de rocas, tormentas eléctricas, cambios bruscos de temperatura o de la velocidad del viento, nevazones o lluvias intensas, etc., ya mencionados.

Respecto de los riesgos asociados al propio embalse, hay una señalización que prohíbe el baño, ubicada en el principal mirador a este cuerpo de agua (Figura 16). Dicho lugar no cuenta con infraestructura adecuada según estándares vigentes para espacios de uso público como senderos, barandas u otro elemento de protección y/o información al visitante.

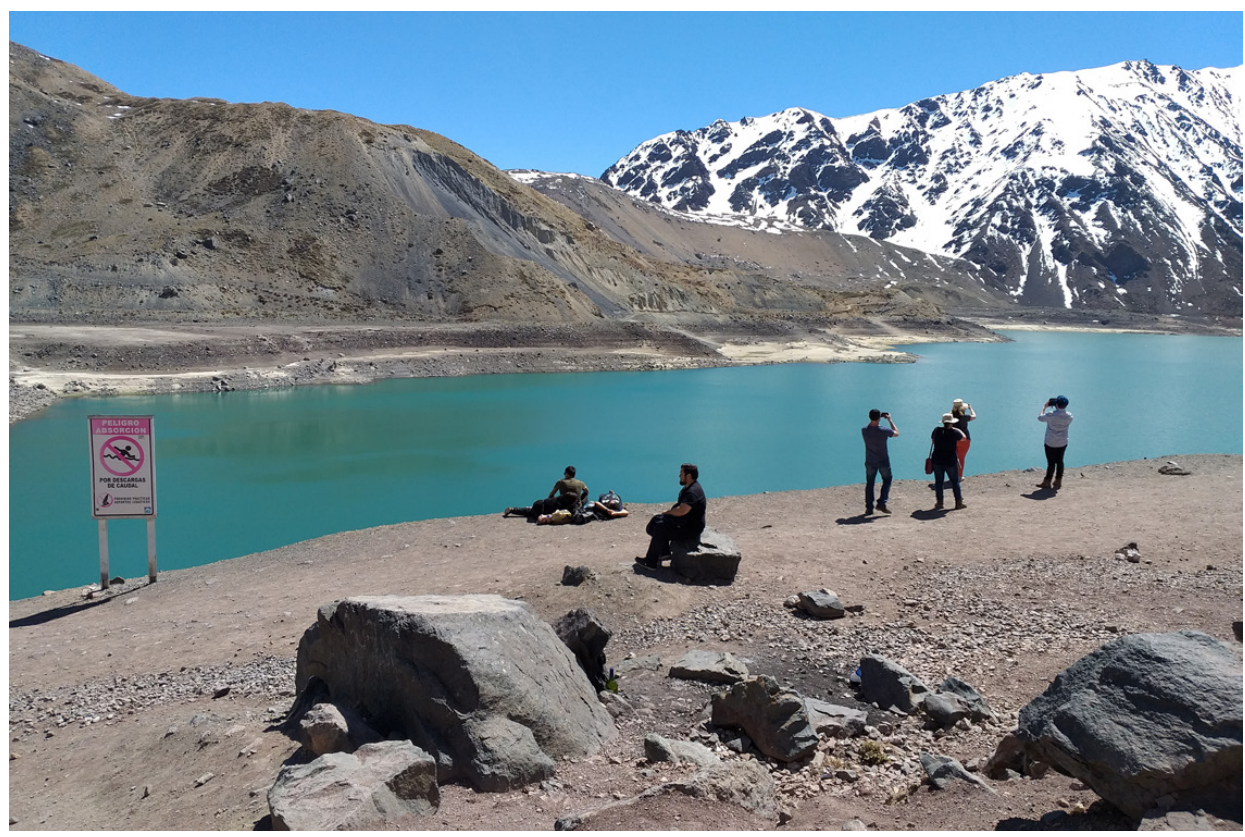

Figura 16. Señalización en uno de los miradores al embalse, cercano al acceso a este, que indica prohibición de nadar en él por peligro de absorción producto de descargas de agua

Fuente: Autores, 2018 
Consultados algunos comerciantes en el área respecto de la forma en que se actúa en caso de emergencia, estos señalan que si bien no hay un protocolo establecido, ellos bajan hasta sectores donde pueden ubicar a Carabinenos mediante teléfono móvil, quienes acuden al lugar en vehículo. En caso de ser necesario efectuar un rescate, este se ha llevado a cabo mediante helicópteros o vehículos de emergencia, reconociéndose falencias en cuando a la cobertura de telefonía móvil y la falta de implementos de primeros auxilios en la zona más visitada, así como la escasa accesibilidad vehicular.

\section{CONCLUSIONES: LOS DESAFÍOS DE LA INTEGRACIÓN DE LA GESTIÓN DE RIESGOS EN EL EMBALSE EL YESO Y DEL TURISMO DE MONTAÑA EN CHILE}

La pavimentación de cerca de $21 \mathrm{~km}$ de la ruta G -455 hacia el Embalse El Yeso ayudó a incrementar notablemente el flujo de turistas al área en los últimos años, sumado a la priorización de esta zona como destino turístico de nivel internacional en la Región Metropolitana, lo cual ha sido refrendado por diversas políticas públicas y planes para el fomento de la actividad turística desarrollados por distintos organismos del estado.

Sin embargo, esto no ha estado acompañado de la implementación de infraestructura adecuada para el desarrollo del turismo en la zona del Cajón del Maipo y no ha tomado en consideración las amenazas geológicas e hidrometeorológicas que afectan al sector, salvo en las zonas urbanas de la comuna incluidas en el Plan Regulador.

La prohibición de ingreso de vehículos motorizados al embalse durante el invierno disminuye la posibilidad de accidentes, pero no necesariamente reduce otros riesgos a los que se exponen los turistas que visitan el área. Por otro lado, el problema asociado a los estacionamientos solo se traslada unos kilómetros más lejos del embalse, sin que exista claridad respecto de cómo ello será resuelto o si se mantendrán los vehículos estacionando en el costado de la calzada.

Dada la importancia que adquiere el turismo como actividad económica en el desarrollo local de las comunas de montaña como San José de Maipo, así como las condiciones específicas de estos territorios expuestos a amenazas geológicas e hidrometeorológicas, algunas de las cuales pueden verse exacerbadas por el cambio climático, se hace necesario que la planificación de las ZOIT así como de otros destinos de montaña y sus planes de acción consideren los peligros presentes y ejecuten acciones adecuadas para la reducción y gestión de los riesgos que pueden afectar a visitantes y residentes, en desmedro del desarrollo económico y social que se busca potenciar por medio del turismo

Si bien existen avances en la homologación de estándares para los turoperadores que ofrecen servicios turísticos en montaña - principalmente de turismo aventura- en cuanto a la gestión de los riesgos de su actividad, ello no es suficiente considerando que muchos visitan estas zonas de manera independiente y no necesariamente cuentan con información o formación suficiente que implique conocer los peligros en las zonas que visitan y saber qué hacer en caso de emergencia.

Resulta, por tanto, necesario conocer, estudiar y zonificar los riesgos a nivel local en los destinos turísticos priorizados, tales como la zona del Cajón del Maipo y el Embalse El Yeso en particular, como elemento central de su ordenamiento y gestión. La gestión de riesgos debe integrar a turoperadores, municipio, los propietarios de los terrenos, comunidad local, otros miembros del sistema de protección civil y organismos del Estado que ejecuten obras o inversiones en la zona tales como el Ministerio de Obras Públicas, el Ministerio de Vivienda (principalmente en áreas urbanas) y otros como la Subsecretaría de Turismo, SERNATUR, FOSIS ${ }^{1}$ y CORFO².

En los destinos de montaña, altamente frágiles desde el punto de vista ambiental, como muchos en la Cordillera de los Andes, donde además de las amenazas naturales y antrópicas ya mencionadas, la actividad turística en sí misma puede constituir un peligro para la conservación de los ecosistemas o de los servicios ambientales que estos territorios prestan (como fuente de agua, por ejemplo), resulta aún más relevante una gestión integral del destino, que considere su capacidad de carga y la aplicación de medidas para asegurar un turismo sostenible.

Lo anterior es consistente con lo señalado en el Marco de acción de Sendai (UNISDR, 2015) que considera en su prioridad 3 , invertir en la reducción del riesgo de desastres para la resiliencia, "promover e integrar enfoques de gestión del riesgo de desastres en toda la industria del turismo, habida cuenta de que a menudo se depende en gran medida del turismo como factor clave para

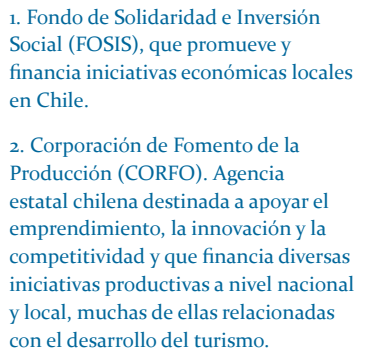


impulsar la economía" (UNISDR, 2015, p.20), acción que se considera prioritaria a nivel nacional y local. Y se relaciona también directamente con la contribución que debiera tener el turismo en el cumplimiento de los objetivos de desarrollo sostenible, particularmente en cuanto a la meta 8.9, del objetivo 8, Promover el crecimiento económico sostenido, inclusivo y sostenible, el empleo pleno y productivo y el trabajo decente para todos, en cuanto a "elaborar y poner en práctica políticas encaminadas a promover un turismo sostenible que cree puestos de trabajo y promueva la cultura y los productos locales". (ONU, s/f).

Así, el cumplimiento de Chile respecto de los acuerdos establecidos en la Agenda 2030 respecto del desarrollo sostenible y del Marco de Sendai, en cuanto a la reducción del riesgo de desastres, están intrínsecamente ligados y resultan evidentes en los destinos turísticos de montaña, altamente expuestos a amenazas y vulnerables al cambio climático, en un contexto donde el turismo como actividad económica es cada vez más importante, siendo priorizado por diversas políticas públicas nacionales.

Ello se refrenda también a nivel internacional, dado que después de las costas y las islas, las montañas son los destinos turísticos más importantes a nivel mundial, alcanzando estimadamente entre un 15 y 20 por ciento de la industria turística global (Price et al., 1997, en Scott, 2017), siendo su importancia creciente a nivel mundial y muy relevante en el desarrollo económico de las comunidades que habitan áreas montañosas (Scott, 2017, p.54).

Pero las acciones arriba mencionadas constituyen esfuerzos en el largo plazo y, no debe olvidarse el riesgo actualmente presente en la actividad turística de montaña en Chile.

En este sentido, resulta también relevante incluir medidas a nivel local posibles de implementar en un corto plazo tales como campañas de educación y difusión, tanto en verano como en invierno $y$, sobre todo, elementos informativos en los destinos, tales como señales e infografías específicas que aborden aspectos básicos sobre las distintas amenazas, señalen los sectores más expuestos, indiquen medidas preventivas y procedimientos básicos en caso de emergencia, como mínimo.

Es crucial que el desarrollo del turismo de montaña en Chile considere integralmente la gestión de riesgos en toda temporada, involucrando a los distintos actores y la condición vulnerable de la actividad turística y los destinos propiamente tales (en cuanto ecosistemas y sus servicios ambientales) respecto del cambio climático y de otras amenazas. Esto presenta tremendos desafíos, que se ven aumentados por la existencia de otras actividades no siempre compatibles que se desarrollan en la misma zona, como la minería y la producción de energía, entre otras, dejando de manifiesto que en este como en otros casos, se requiere una política nacional de ordenamiento territorial que tenga como objetivo principal el desarrollo sostenible y armónico en el territorio.

\section{NOTA DE LOS AUTORES}

Con posterioridad a la presentación de este artículo para su revisión, el 3 de junio de 2019, dos turistas brasileñas - de 3 y 7 años- que visitaban el embalse con sus familias en un grupo guiado por un turoperador, fallecieron a causa de un rodado de rocas ocurrido desde la ladera adyacente al camino. A pesar de la existencia de una barrera que impedía el ingreso de vehículos, accedieron al área caminando, señalando que no existía señalización que advirtiera del peligro en la zona. Una tercera niña resultó herida, señalando quien además de ser su padre era médico: "Empecé a hacer solo las primeras atenciones y tuve que bajar con ella en los brazos todo el camino y cuando llegué abajo, infelizmente no había una ambulancia que podría haber tenido algún soporte avanzado para ayudar en la situación" (La Nación, 2019).

Desde el 6 de septiembre de 2019, el camino al embalse se encuentra cerrado desde el km 21,7 al tránsito vehicular y peatonal a partir de una resolución de la Gobernación Provincial de Cordillera, basada en información de SERNAGEOMIN, que indica que: la ladera adyacente a la ruta se encuentra en una situación geológicamente inestable, no garantizando la seguridad de quienes transiten por ahí, con probabilidades de que se generen nuevas caídas de rocas o rodados. Dicho organismo señala que el cierre debe mantenerse hasta contar con los resultados de un estudio geológico que servirá de insumo para un análisis de riesgos que realizaría ONEMI con el apoyo técnico de SERNAGEOMIN. La resolución recoge la recomendación de ONEMI en cuanto a mantener cerrada la ruta hasta que existan medidas de prevención y mitigación adecuadas (Ministerio del Interior y Seguridad Pública, 2019). 


\section{REFERENCIAS}

AES Gener. (2015). Alto Maipo finaliza pavimentación de rutas en los sectores Yeso y Volcán. Recuperado de: http://www.altomaipo.com/noticias/Paginas/Alto-Maipo-finaliza-pavimentacionde-rutas-en-los-sectores-Yeso-y-Volcan.aspx [visitado el 10 Jul. 2019]

Arriagada, C., Vargas, G., González, J., Gómez, I., Peña, M., Villalobos, A. \& Bascuñan, S. (2015). Geología del valle del río Yeso. GL-6101. GEOLOGIA DE CAMPO II. Santiago de Chile: Facultad de Ciencias Físicas y Matemáticas, Universidad de Chile.

Chilevisión. (2017). Tres desaparecidos y mil aislados en San José de Maipo. La situación concentra a autoridades y al Ejército para ir en ayuda lo más rápido posible. Recuperado de: https://www.chvnoticias.cl/trending/tres-desaparecidos-y-mil-aislados-en-san-jose-de-maipo_20170226/[visitado el 5 de nov. 2018]

El Mercurio Online EMOL. (2017). ¿Cuánto gastan, de dónde son y qué lugares visitan los extranjeros que llegan a Chile? Recuperado de: https://www.emol.com/noticias/Economia/2017/o7/28/868675/ Cuanto-gastan-y-de-donde-son-los-extranjeros-que-llegan-a-Chile.html [visitado el 15 de sep. 2018]

Fredericksen, N., Astorga, B. \& Morales, F. (2010). Santiago Andino. La mayor reserva natural de agua de la Región Metropolitana. Sistemas de Producción Sustentable para Ecosistemas de Montaña. Registro № 200.236. Santiago de Chile: Registro de Propiedad Intelectual de Chile.

García, J.L., Pizarro, F.I. \& Calcagni, V. (2014). Fluctuaciones glaciales holocénicas en el Cajón del Maipo, Andes centrales de Chile: observaciones morfoestratigráficas de los valles del Morado y Nieves Negras. En A. Borsdorf, R. Sánchez, R. Hidalgo \& H.M.Zunino (Eds.). Los riesgos traen oportunidades. Transformaciones globales en Los Andes sudamericanos. Serie GEOlibros $N^{\circ} 20$. Santiago de Chile: Andros, Instituto de Geografía de la Pontificia Universidad Católica de Chile, Instituto Interdisciplinario para Estudios de la Montaña IGF de la Academia de Ciencias Austriaca, Instituto de Geografía de la Universidad de Innsbruck \& Universidad de La Frontera.

Gobierno de Chile. (s/f). Estrategia Nacional de Turismo 2012-2020. Santiago de Chile: Gobierno de Chile. Recuperado de: http://www.subturismo.gob.cl/wp-content/uploads/2015/10/EstrategiaNacional-de-Turismo-2012-2020.pdf [visitado el 25 de oct. 2018]

Gobierno Regional Metropolitano de Santiago \& Consultorías Profesionales Agraria Ltda. (2017). Diagnóstico Planes Marco de Desarrollo Territorial (PMDT) Territorio Prioritario 3, cuarto informe de avance, Subterritorio 9 San José de Maipo. Santiago de Chile: GRMS \& CPA Ltda.

Gobierno Regional Metropolitano de Santiago \& Secretaría Regional Ministerial Metropolitana del Ministerio del Medio Ambiente. (2013). Estrategia Regional para la Conservación de la Biodiversidad en la Región Metropolitana de Santiago 2015-2025. Licitación 1261-3- LP12/2012. Código BIP $N^{\circ} 30096753-0$. Santiago de Chile: GRMS.

La Nación. (2019). Padres de niñas brasileñas muertas en Embalse El Yeso: "no había señalización". Recuperado de: http://lanacion.cl/2019/o6/o7/padres-de-ninas-brasilenas-muertas-en-embalse-el-yeso-no-habia-senalizacion/ [visitado el 10 de oct. 2019]

La Tercera. (2018a). Carabineros rescata a personas aisladas en San José de Maipo por rorado. Recuperado de: https://www.latercera.com/nacional/noticia/carabineros-rescata-personas-aisladas-san-jose-maipo-rodado/57478/ [visitado el 5 de nov. 2018]

La Tercera. (2018b). Rescatan a familia atrapada en Embalse El Yeso. Recuperado de: https://www. latercera.com/nacional/noticia/rescatan-familia-atrapada-embalse-yeso/323993/ [visitado el 19 de sep. 2018]

Ministerio de Economía, Fomento y Turismo, Subsecretaría de Turismo. (2019). Apruébase el Reglamento para la Aplicación del Sistema de Clasificación, Calidad y Seguridad de los Prestadores de Servicios Turísticos. Diario Oficial, publicado el 12 de abril de 2019. Santiago de Chile: Ministerio de Economía, Fomento y Turismo.

Ministerio de Economía, Fomento y Reconstrucción. (2010). Ley 20.423 Del Sistema Institucional para el Desarrollo del Turismo. Diario Oficial, publicado el 12 de febrero de 2010. Santiago de Chile: Ministerio de Economía, Fomento y Reconstrucción.

Ministerio de Obras Públicas, Ministerio de Economía, Fomento y Turismo \& Subsecretaría de Turismo. (2017). Plan Especial de Infraestructura MOP de apoyo al Turismo Sustentable a 203o. Santiago de Chile: Subsecretaría de Turismo - Dirección de Planeamiento MOP.

Ministerio de Transportes y Telecomunicaciones, Subsecretaría de Transportes \& Secretaría Regional Ministerial de la Región Metropolitana. (2018). Resolución Exenta №5615/2018 Prohíbe circulación de vehículos motorizados en Ruta G-455 (Camino El Yeso) y Ruta G-355 (Camino Lagunillas) en los términos que indica. Promulgado 5 de septiembre de 2018. Diario Oficial, 2 de octubre de 2018. Santiago de Chile: Gobierno de Chile. 
Ministerio del Interior y Seguridad Pública \& Gobernación de Cordillera (2019). Prohíbe el ingreso peatonal y vehicular en la Ruta G-455 (Camino al Embalse El Yeso), en la comuna de San José de Maipo desde el km 21,7 hasta que el Servicio Nacional de Geología y Minería del Ministerio de Minería de Chile, lo indique. Diario Oficial, 3 de septiembre de 2019. Santiago de Chile: Gobierno de Chile.

Oficina de las Naciones Unidas para la Reducción del Riesgo de Desastres UNISDR. (2015). Marco de Sendai para la Reducción del Riesgo de Desastres 2015-2030. Ginebra: UNISDR.

Organización de las Naciones Unidas ONU (s/f). Objetivo 8: Promover el crecimiento económico sostenido, inclusivo y sostenible, el empleo pleno y productivo y el trabajo decente para todos. Ginebra: ONU. Recuperado de: https://www.un.org/sustainabledevelopment/es/economic-growth/ [visitado el 22 de oct. 2018]

Pizarro-Tapia, R., Cabrera-Jofré, C., Morales-Calderón, C. \& Flores-Villanelo, J.P. (2011). Variación temporal de las precipitaciones y caudales en la cuenca del Maipo, y la potencial influencia glaciar en la producción de agua (1963-2006). Tecnología y Ciencias del Agua, antes Ingeniería hidráulica en México, 2(3), 5-19.

Puente Alto Al día. (2016). Una persona fallece al caer a las aguas del Embalse El Yeso. Recuperado de: http://puentealtoaldia.cl/ultimas-noticias/una-persona-fallece-al-caer-a-las-aguas-del-embalse-delyeso/ [visitado el 5 de nov. 2018]

Servicio Nacional de Geología y Minería SERNAGEOMIN. (2017). Catastro de los principales desastres naturales por peligros geológicos en Chile y efectos sobre la población y bienes públicos y privados entre 1980 y 2015. Santiago de Chile: SERNAGEOMIN.

Servicio Nacional de Turismo SERNATUR. (s/f). Guía para la Implementación de Normas de Calidad Turística Turismo Aventura. Recuperado de: http://www.calidadturistica.cl/archivos/guias/Guiapara-la-implementacion-de-Guias-de-Turismo-Aventura.pdf [visitado el 10 de nov. 2018]

Servicio Nacional de Turismo SERNATUR. (2014). Plan de Acción Región Metropolitana Sector Turismo 2014-2018. Santiago de Chile: SERNATUR.

Subsecretaría de Turismo (s/f.a). Antecedentes ZOIT San José de Maipo. Recuperado de: http://www. participacionciudadana.economia.gob.cl/sites/default/files/ZOIT\%2oSan\%2oJosé\%2ode\%2oMaipo. pdf [visitado el 1o de oct. 2018]

Subsecretaría de Turismo (s/f.b). Mesa de seguridad turística. Recuperado de: http://www.subturismo. gob.cl/mesa-de-seguridad-turistica/ [visitado el 27 de oct. 2018]

Scott, D. (2017). Global environmental change and mountain tourism. En Stefan Gössling \& C. Michael Hall (Eds.) Tourism and Global Environmental Change: Ecological, social, economic and political interrelationships. Nueva York, EEUU: Routledge, pp.54-75.

Universidad de Chile. (2018). Académicos preparan a la población de San José de Maipo para hacer frente a las emergencias. Elaboran plan maestro. Recuperada de: http://www.uchile.cl/noticias/143821/ academicos-elaboran-plan-maestro-para-preparar-gente-ante-emergencias. 25 mayo 2018 [visitado el 12 de oct. 2018] 